NBER WORKING PAPER SERIES

\title{
EAT OR BE EATEN: \\ A THEORY OF MERGERS AND MERGER WAVES
}

\author{
Gary Gorton \\ Matthias Kahl \\ Richard Rosen \\ Working Paper 11364 \\ http://www.nber.org/papers/w11364 \\ NATIONAL BUREAU OF ECONOMIC RESEARCH
1050 Massachusetts Avenue
Cambridge, MA 02138 \\ May 2005
}

The views in this paper are those of the authors and may not represent the views of the Federal Reserve Bank of Chicago or the Federal Reserve System. We thank Amit Goyal and Feifei Li for excellent research assistance. We are grateful for helpful comments and suggestions by Andres Almazan, Antonio Bernardo, Sanjai Bhagat, Bhagwan Chowdhry, Michael Fishman, S. Viswanathan, Ivo Welch, seminar participants at Purdue University and the University of Wisconsin-Madison, and conference participants at the AFA 2000 meetings and the Texas Finance Festival 2000. This is a substantially revised version of an early draft that was presented at these conferences. Of course, all remaining errors and shortcomings are solely our responsibility. The views expressed herein are those of the author(s) and do not necessarily reflect the views of the National Bureau of Economic Research.

(O2005 by Gary Gorton, Matthias Kahl, and Richard Rosen. All rights reserved. Short sections of text, not to exceed two paragraphs, may be quoted without explicit permission provided that full credit, including $\odot$ notice, is given to the source. 
Eat or Be Eaten: A Theory of Mergers and Merger Waves

Gary Gorton, Matthias Kahl, and Richard Rosen

NBER Working Paper No. 11364

May 2005

JEL No. G3

\begin{abstract}
In this paper, we present a model of defensive mergers and merger waves. We argue that mergers and merger waves can occur when managers prefer that their firms remain independent rather than be acquired. We assume that managers can reduce their chance of being acquired by acquiring another firm and hence increasing the size of their own firm. We show that if managers value private benefits of control sufficiently, they may engage in unprofitable defensive acquisitions. A technological or regulatory change that makes acquisitions profitable in some future states of the world can induce a preemptive wave of unprofitable, defensive acquisitions. The timing of mergers, the identity of acquirers and targets, and the profitability of acquisitions depend on the size of the private benefits of control, managerial equity ownership, the likelihood of a regime shift that makes some mergers profitable, and the distribution of firm sizes within an industry.

Gary Gorton

Department of Finance

The Wharton School

University of Pennsylvania

Philadelphia, PA 19104-6367

and NBER

gorton@wharton.upenn.edu

Matthias Kahl

University of North Carolina at Chapel Hill

matthias.kahl@unc.edu

Richard Rosen

Federal Reserve Bank of Chicago

richard.rosen@chi.frb.org
\end{abstract}




\section{Introduction}

The 1990s saw the greatest U.S. merger wave ever. Every year from 1995 to 2000 generated a new record for U.S. merger volume, starting from $\$ 800$ billion in 1995 - the record at that time - to $\$ 1.8$ trillion in $2000 .^{1}$ Several industries experienced dramatic merger waves, including commercial banking, telecommunications, investment banking, hotels and casinos, and oil and gas. Due to the importance of mergers, there is a vast academic literature on the topic. However, existing merger theories have difficulties reconciling the stylized facts about mergers.

Two of the most important stylized facts about mergers are the following: First, acquirer returns are, on average, negative. ${ }^{2}$ Second, mergers concentrate in industries for which a regime shift of technological or regulatory nature can be identified, one that arguably makes mergers an efficient response (see, for example, Mitchell and Mulherin (1996), Andrade, Mitchell, and Stafford (2001), and Andrade and Stafford (2004)). These two stylized facts are difficult to reconcile theoretically. The view that mergers are an efficient response to regime shifts by valuemaximizing managers (see, for example, Mitchell and Mulherin (1996), Weston, Chung, and Siu (1998), and Jovanovic and Rousseau (2002)) can explain the second stylized fact. However, it has difficulties explaining negative abnormal returns to acquirers. Theories based on managerial selfinterest or a desire for larger firm size and diversification (for example, Morck, Shleifer, and Vishny (1990)) can explain negative acquirer returns. ${ }^{3}$ However, they cannot explain why mergers are concentrated in industries for which a regime shift can be identified that may make mergers an efficient response.

These observations suggest that it might be promising to combine elements of the neoclassical and the managerial merger theories. This paper provides a theory of mergers that combines elements of these two merger theories and reconciles the above two stylized facts. Moreover, it

\footnotetext{
${ }^{1}$ See "The Year of the Mega Merger...”, Fortune Magazine, January 11, 1999, “Tales of the Tape: '99 M\&A Vol Hits Record...”, Dow Jones News Service, December 29, 1999, and "Year-End Review of Markets \& Finance 2000..”, The Wall Street Journal, January 2, 2001.

${ }^{2}$ Studies that find negative average returns to bidders include Asquith, Bruner, and Mullins (1987), Banerjee and Owers (1992), Bradley, Desai, and Kim (1988), Byrd and Hickman (1992), Jennings and Mazzeo (1991), Servaes (1991), Varaiya and Ferris (1987), and You, Caves, Smith, and Henry (1986). See Table 86 in Gilson and Black (1995). See also the recent survey by Andrade, Mitchell, and Stafford (2001). Note that smaller acquirers do better on average than larger acquirers (Kahl and Rosen (2002) and Moeller, Schlingemann, and Stulz (2004)).

${ }^{3}$ Other papers in which managerial motivations for mergers are prominent include Amihud and Lev (1981), Shleifer and Vishny (1989), and May (1995). Theoretical papers representing the neo-classical tradition include Gort (1969) and Rubin (1973). Negative acquirer announcement returns can be explained without appealing to agency conflicts between managers and owners if the takeover announcement reveals negative information about the acquirer's profitability relative to expectations (see McCardle and Viswanathan (1994) and Jovanovic and Braguinsky (2004)).
} 
can explain a third stylized fact, namely, that mergers often come in waves. A regime shift that may make mergers efficient is a key part of our analysis. However, one particular managerial motive - the desire not to be acquired - is also important. The paper characterizes the timing of mergers, the identity of acquirers and targets, and the profitability of acquisitions. Testable implications related to these issues are developed.

The basic elements of our theory are the following: First, managers may have a preference for keeping their firms independent. Managers of acquired firms are likely to play subordinated roles in the new firms or may even lose their jobs (Morck, Shleifer, and Vishny (1988)). The second element of our model is that there is a state of the world in which at least some mergers generate value. In contrast to other papers on managerial acquisition motives, such as Morck, Shleifer, and Vishny (1990), there would be no unprofitable acquisitions in our model if there were no possibility of profitable acquisitions. Third, we assume that a firm of given size cannot acquire a larger firm. The larger the acquisition, the more difficult it is to finance. Typically, it will be more difficult to raise funds by issuing debt for a larger acquisition. Potential acquirers may be reluctant to incur a lot of debt, which would increase the chance of financial distress substantially. Managers of financially distressed firms are more likely to lose their jobs (see Gilson (1989)). Acquiring a larger company with stock would dilute the acquirer's ownership of the combined company and perhaps lead to a loss of control for incumbent management. These difficulties in acquiring larger companies may explain why in most mergers the acquirer is substantially larger than the target. The assumption that a firm cannot acquire a firm that is larger than itself implies that a firm can reduce its chance of being acquired by acquiring another firm. This increases its size, which then reduces the number of other firms that are potential acquirers; there are fewer firms that are sufficiently large. In fact, empirically it has been found that the probability of being a target in an acquisition is decreasing in a firm's size (e.g., see Hasbrouck (1985) and Palepu (1986)). ${ }^{4}$

In such an environment, we show that two entirely different merger dynamics may unfold. In the first scenario only profitable acquisitions occur (the "efficient” scenario). In the other sce-

\footnotetext{
${ }^{4}$ That acquiring another firm does, in fact, reduce the chance of being acquired is also consistent with the small amount of available evidence. Louis (2004) finds that banks that were potential takeover targets and subsequently made an acquisition themselves were less likely to be taken over than banks that were a potential takeover target but that did not make an acquisition themselves. He also finds that banks that were potential takeover targets and that engaged subsequently in a (presumably defensive) acquisition paid higher premia and experienced worse cumulative abnormal returns than other banks. These findings are consistent with our predictions for defensive acquisitions.
} 
nario (the "eat-or-be-eaten” scenario ${ }^{5}$ ) defensive, unprofitable acquisitions that preempt some profitable acquisitions occur. Which scenario arises depends on the incentives of managers to make defensive acquisitions. If managers are less interested in remaining independent (and gaining the associated private benefits) than in maximizing shareholder value (because their compensation depends on it), there is no defensive merger pressure. No firm will acquire another firm if this is unprofitable, and hence all mergers lead to positive returns for both the target and the acquirer.

However, if managerial desire not to be acquired is sufficiently strong, then the merger dynamics change dramatically. Now managers are tempted to engage in defensive acquisitions to secure the independence of their firms - perhaps well before the regime shift has made the acquisitions profitable. (In fact, the regime shift may never occur.) This defensive merger motive is self-reinforcing: Because some managers feel the need to secure the independence of their firms by making defensive acquisitions, other managers are driven to protect the independence of their own firms by making defensive acquisitions themselves. Defensive mergers come in waves. The intuition for merger waves is as follows. Even if only one firm (call it Firm 1) has an efficient and hence profitable acquisition opportunity in the future, several other firms may be induced to engage in defensive acquisitions to ensure their survival as independent firms. Anticipating that Firm 1 may acquire it if a regime shift makes mergers profitable, a potential target firm (call it Firm 2) may acquire another firm (Firm 5) to become large enough to deter the takeover offer. But this makes other potential targets (Firms 3 and 4) more vulnerable to the acquisition by Firm 1 and hence induces them to make defensive acquisitions as well. Hence, several firms - all potential takeover targets - may each attempt to make a defensive acquisition, and each firm's defensive acquisition makes the other firms more likely to be left as the most attractive target if they do not themselves engage in a defensive acquisition. Hence, the potentially profitable acquisition opportunity for one firm can lead to an "eat or be eaten” merger wave. Merger waves arise because of the externalities involved in defensive mergers: One firm's defensive acquisition makes other firms more vulnerable as takeover targets, which induces them to make defensive acquisitions themselves, resulting in a race for firm size.

\footnotetext{
${ }^{5}$ Many articles in the press or trade journals mention the idea that if firms do not make acquisitions, they may become targets themselves. Often, they refer to the ensuing merger dynamics as "eat or be eaten" (see, for example, "For Military Contractors, It's Buy or Be Bought”, New York Times, March 12, 1994, "Phone Giants Reportedly Mulling Merger", Los Angeles Times, May 11, 1998, and "Middle-market M\&A players: Where are they now?”, Bank Mergers \& Acquisitions, August 1, 2002). Sometimes these articles explicitly discuss the role that firm size can play in who can acquire whom (see, for example, "New England Utility Mergers Raise Question over Boston Edison’s Future”, KRTBN Knight-Ridder Tribune Business News: The Boston Globe - Massachusetts, June 16, 1999, and "Takeover Rumors Fuel Another Rise in Amgen Stock...”, The Los Angeles Times, August 30, 1994).
} 
We show that defensive, unprofitable acquisitions can preempt profitable acquisitions. In this case, there are more mergers than in the absence of managerial defensive motives, they occur too early, and the acquirers lose money. Even though a regime shift (of a technological or regulatory nature) may, in principle, allow profitable acquisitions, it can have the effect of inducing a defensive wave of unprofitable acquisitions.

Our theory also emphasizes the importance of the industry structure - the distribution of firm sizes in the industry - for merger dynamics. If many firms are of similar size, the defensive merger waves of unprofitable acquisitions discussed above are likely if managers care enough about staying in control, i.e., private benefits are high. However, if the largest firm with a profitable acquisition opportunity (Firm 1) is much larger than the other firms in the industry, the merger dynamics are very different. Now no firm can defend itself against acquisitions by Firm 1 by acquiring another firm. Indeed, acquiring other firms has the opposite effect of making the firm larger, and hence a more attractive takeover target (if synergies are increasing in the target firm's size). If managers care enough about preserving the independence of their firms, they avoid acquisitions. But, if managers care a lot about firm value, i.e., private benefits are low, they may engage in acquisitions of other firms in order to become larger and hence a more attractive target (for the firm with profitable acquisition opportunities). This can lead to a merger wave preceding the regime shift that makes mergers efficient. In this case, all acquisitions will be profitable, because the early acquisitions are undertaken to increase the likelihood of being the target in a wealth-creating merger later.

Our theory also generates predictions on the identity of acquirers and targets and on the relationship between acquirer and target size and the profitability of acquisitions. To address these issues, we consider an industry in which some but not all firms are of similar size. This means that firms of intermediate size have both the opportunity to make defensive acquisitions (that make them large enough to be protected from takeovers) as well as profitable acquisitions that make them more attractive takeover targets. We show that, with the exception of the largest firm (which has no defensive motives and hence only undertakes profitable acquisitions), the profitability of acquisitions is decreasing in the acquirer's size. Large firms engage only in defensive, unprofitable acquisitions, which occur if private benefits are high. Firms of intermediate size engage in defensive (unprofitable) acquisitions under some circumstances, but under other circumstances they engage in profitable acquisitions. The profitability of their acquisitions decreases in 
the ratio of the target's size to the acquirer's size. Finally, small firms typically engage in profitable acquisitions. ${ }^{6}$

Our theory can explain the three stylized facts about mergers mentioned above - that acquirers, on average, lose money, mergers concentrate in industries in which regime shifts can be identified, and mergers come in waves. It is also consistent with the evidence on defensive acquisitions in the U.S. banking industry presented by Louis (2004), who shows that banks engaging in defensive acquisitions are less likely to be acquired subsequently and defensive acquisitions lead to worse abnormal returns to acquirers. Our theory generates a number of other empirical predictions. For example, we predict that acquirer returns are negatively correlated with acquirer size as well as target size (consistent with the results in Kahl and Rosen (2002), Moeller, Schlingemann, and Stulz (2004), and Kahl and Valkanov (2004)), that acquirer announcement returns for medium sized firms decrease in the ratio of target to acquirer size, that medium sized firms are most likely to acquire other firms, and that industries in which some but not all firms are of similar size are most likely to exhibit merger waves. These and other empirical implications are discussed in more detail in section VI.

Our paper is related to two strands of the theoretical literature. In Financial Economics there are several related papers. Harris (1994) presents a model that determines which firm is the acquirer and which firm the target in a value-increasing merger. She also assumes that managers have a preference for being the acquirer rather than the target in an acquisition. In contrast to our paper, Harris (1994) assumes that all mergers are value creating. The most important difference between her paper and ours is that we analyze merger dynamics involving several firms while her model is static and involves only two firms. This allows us to generate results on the timing of mergers, on merger waves, and on the effect of the distribution of firm sizes in an industry on the merger dynamics, the identity of acquirers and targets, and the profitability of acquisitions.

Shleifer and Vishny (2003) argue that merger waves are driven by misvaluations in the stock market. Rational managers take advantage of these irrational misvaluations through mergers and acquisitions $^{7}$ (for empirical evidence supporting this theory see Ang and Cheng (2003), Dong, Hirshleifer, Richardson, and Teoh (2003), and Rhodes-Kropf, Robinson, and Viswanathan (2004)). Rhodes-Kropf and Viswanathan (2004) show that even in a rational model with efficient markets stock market booms can lead to merger waves. While we abstract from stock market valuation effects on merger activity to focus on the impact of managerial incentives and regime

\footnotetext{
${ }^{6}$ However, there is one unprofitable acquisition by a small firm for very high private benefits in our model. This acquisition secures the independence of the small firm for one, but not two, periods.

${ }^{7}$ However, Harford (2004) finds that industry shocks and sufficient liquidity in the capital markets are
} 
shifts in industries, we do not mean to suggest that stock market valuations do not have an important impact on merger dynamics. Roll (1986) argues that it is not surprising that acquisitions may not add value or even reduce value because they may be the result of decisions by overconfident managers who overestimate the value of the target or their ability to manage it, running into the winner's curse associated with auctions (for empirical evidence supporting the hubris hypothesis, see, for example, Rau and Vermaelen (1998) and Malmendier and Tate (2003)). He is not interested in characterizing the dynamics of merger waves. Moreover, Roll's hubris hypothesis alone cannot explain why mergers concentrate in industries for which a regime shift can be identified.

Lambrecht (2004) analyzes the timing of mergers motivated by economies of scale and shows that mergers are procyclical. Morellec and Zhdanov (2004) present a dynamic merger model that determines the timing and terms of takeovers. Both papers emphasize the real options aspects of merger decisions. Toxvaerd (2004) analyzes strategic merger waves. In his paper, acquirers compete over time for a scarce set of targets. The trade-off between the option value of waiting for better market conditions and the fear of being preempted by other acquirers and hence being left without a merger partner determines the merger timing. This can give rise to strategic merger waves. In contrast to our paper, none of these papers considers managerial acquisition incentives or the importance of size as a takeover deterrent.

There is a second literature on mergers in Industrial Organization, which has its beginnings in Ericson and Pakes (1995). The basic model considers a finite number of firms, sequential investments with stochastic outcomes, entry and exit. This framework has been extended to include mergers (e.g., Gowrisankaran (1999)). These models cannot be solved analytically. This literature has evolved to a point where post-merger outcomes, based on pre-merger estimated consumer demands, and assumed pricing behavior, is simulated (e.g., Berry and Pakes (1993), Baker (1997), Epstein and Rubinfeld (2001), Peters (2003)). The main focus of this literature is the post-merger pricing behavior of firms with respect to consumer welfare issues. ${ }^{8}$ Corporate governance and managerial considerations do not play a role in the merger decisions. However, the literature illustrates many of the modeling issues that must be confronted in analyzing mergers. In order to make the models tractable and reduce the potentially large multiplicity of equilibria, one has to make strong assumptions concerning the assumed choice of merger decision protocol (e.g., the order in which firms decide on whether to merge), initial industry size distribution (e.g., many firms of the same size, one dominant firm, etc.), division of any surplus between merging entities, and so on. We also have to make strong assumptions on the merger protocol, which allows us to

more important in causing merger waves than market timing attempts by managers.

${ }^{8}$ Gowrisankaran and Holmes (2004) analytically analyze the effect of mergers on industry concentration. 
generate one of the first tractable dynamic merger models with heterogeneous firm sizes that endogenizes the identity of acquirer and target and can generate merger waves. It is, to our knowledge, the first such model that allows for managerial acquisition incentives.

The remainder of the paper is structured as follows: Section I presents the basic model with three firms. Section II extends the model to five firms of similar size, which allows us to analyze merger waves. Section III offers a model with a dominant firm that shows that the distribution of firm sizes within an industry is a crucial determinant of merger dynamics. Section IV presents a model in which some but not all firms are of similar size. Section V discusses some of the assumptions of our models. Section VI presents some additional empirical implications of our theory. Section VII concludes.

\section{The Basic Model}

This section presents a model of defensive mergers. A defensive merger is one that is value reducing for shareholders, but that allows the managers of the acquiring firm to have a better chance of retaining their jobs. So, while a defensive merger is done to increase the private benefits of managers, it would not be undertaken in the absence of a takeover threat. ${ }^{9}$ In this section, we show that the desire by managers to continue in their jobs can lead to excessive merger activity. This will be shown within a three firm model. In the next section, we extend the model to look at merger waves, for which we need a five firm model. (We choose the minimum number of firms necessary to show the results.)

\section{A. Model Assumptions}

The simplest way to model managerial motivations for mergers is using two dates, 0 and 1 , and three firms. The timing of the model is shown in Figure 1.

The three firms are ordered by their size (stand alone value) $C_{i}$, with $C_{1}>C_{2}>C_{3}$ : Firm 1 is the largest and Firm 3 the smallest. ${ }^{10}$ We assume that firms cannot acquire firms that are larger than they are. This implies that every firm is immune against acquisition attempts by firms that are smaller than it is. Hence, larger firms are less likely to be acquired, since there are fewer firms

\footnotetext{
${ }^{9}$ Obviously, there may be acquisitions done for private benefits that would be done in the absence of a takeover threat (see, for example, Morck, Shleifer, and Vishny (1990) and Bliss and Rosen (2001)). We do not consider such acquisitions in this paper.

${ }^{10}$ In interpreting our models, it should be recognized that antitrust laws put some restrictions on intraindustry or horizontal mergers. This is one reason why the largest firm with a profitable acquisition opportunity (Firm 1) may not necessarily be the largest firm in the industry. Our model considers mergers within an industry that are allowed by antitrust law.
} 
that are larger than they are. As we discussed in the Introduction, there are probably fewer buyers for larger firms since acquiring a larger firm requires more resources and is more likely to lead to a loss of control. ${ }^{11}$ As a consequence of the assumption that a firm cannot acquire a larger firm, Firm 3 cannot acquire another firm, because it is the smallest firm. To make the model interesting, we assume that $C_{2}+C_{3}>C_{1}$, i.e., that after Firm 2 acquires Firm 3, it is larger than Firm 1 and hence cannot be acquired. This gives Firm 2 a potential incentive to acquire Firm 3.

At each date, a manager receives private benefits of $w$ if his firm is not acquired and zero if it is acquired. ${ }^{12}$ The manager of each firm also owns a share $\alpha$ of his firm, which is exogenous for simplicity. All firms resolve indifference between acquiring and not acquiring in favor of not acquiring, perhaps due to unmodeled transactions costs. We assume that contracts cannot fully overcome managerial preference for their firms to remain independent. ${ }^{13}$

We assume that at each date, a firm can make at most one acquisition offer to another firm. Within each period, Firm 1 moves first, Firm 2 moves second, and Firm 3 moves last. The profitability of a merger depends on the identities of the merger partners and on the state of nature, realized at date 1. Each firm can make at most one acquisition over the two dates: If it has made an acquisition at date 0 , it cannot make another one at date 1 . This assumption simplifies the analysis and is discussed in more detail in section V below.

At the start of date 0 firms learn that a regime shift may occur, corresponding to a change in their environment. For example, a fundamental change in technology or government regulation may at some point in the (near) future make acquisitions profitable. The change may generate economies of scale or scope, or it may lead to overcapacity. The key is that the regime shift changes conditions in the industry enough to make some acquisitions possibly profitable, but the probability of this regime shift is low enough such that current acquisitions are not yet profitable for the acquirer.

\footnotetext{
${ }^{11}$ As mentioned in the Introduction, it has been found that the probability of being a target in an acquisition is decreasing in a firm's size (see, e.g., Hasbrouck (1985) and Palepu (1986)).

${ }^{12}$ In reality, private benefits differ across firms and managers and arguably increase in firm size. In a model that captured this cross-sectional variation in private benefits, firms with larger private benefits would be more inclined to engage in defensive acquisitions. Moreover, we conjecture that unprofitable acquisitions would be even more attractive to managers since the higher private benefits that can be obtained in larger firms would give them another reason to make acquisitions in their own interests at the expense of their shareholders. Our assumption of homogenous private benefits allows us to spell out the consequences of one particular managerial motive - survival of the firm as an independent entity - while abstracting from other motives such as general empire-building tendencies that are already well understood in the literature (Baumol (1959), Marris (1964), Jensen (1986), and Jensen (1993)).

${ }^{13}$ An assumption that the agency conflict cannot be fully eliminated through compensation contracts is typically made in the literature (see, e.g., Hart and Moore (1995)).
} 
More concretely, we assume that mergers at date 1 are possibly efficient. Specifically, firms learn at date 0 that the state of nature at date 1 will be good with probability $\rho$ and bad with probability $1-\rho$. In the good state of the world, only Firm 1 has efficient merger opportunities in the sense that if Firm 2 or Firm 3 is combined with Firm 1, it is worth more than its stand alone value of $\mathrm{C}_{2}$ or $\mathrm{C}_{3}$, respectively, perhaps due to synergies (economies of scale and scope).

For simplicity, we assume that if the good state occurs at date 1, Firm 2 and Firm 3 are worth twice as much if combined with Firm 1 than as stand alones: Firm 2 is worth $C_{2}$ as a stand alone, but is worth $2 \mathrm{C}_{2}$ if combined with Firm 1 . Similarly, Firm 3 is worth $\mathrm{C}_{3}$ as a stand alone, but is worth $2 \mathrm{C}_{3}$ if combined with Firm 1 . However, if Firm 2 combines with Firm 3, there are no synergies: their combined value is equal to the sum of their stand-alone values $C_{2}+C_{3}$. Assuming that a combination of Firms 2 and 3 would create value would not change the main results.

In the bad state at date 1, all mergers destroy value. For simplicity, we assume that any target acquired by another firm is worth zero after the merger. Again, this is just a normalization, and it could easily be adjusted without affecting the qualitative results of our analysis.

To make the merger decision interesting, we want mergers to be unprofitable (valuereducing) even for Firm 1 at date 0 . This will be the case if the bad state is more likely than the good state:

(1) $\rho<0.5$.

Firms might make unprofitable acquisitions in our model because we assume that the acquiring firm's managers decide whether or not to make an offer. We concentrate on the motivations to make acquisition offers, but we also have to think about when a target firm will accept an offer. Assume that shareholders of the target firm make the decision about whether to accept an offer. ${ }^{14}$ We assume that target shareholders accept a takeover offer if and only if it involves at least a zero

\footnotetext{
${ }^{14}$ A central idea behind our model is that takeovers can serve a defensive purpose in that an acquisition reduces the probability of being acquired. Hence, defensive acquisitions can be viewed as takeover defenses. Our model ignores other takeover defenses such as poison pills and staggered boards. To the extent that these other takeover defenses can be employed, they may substitute for defensive acquisitions and hence make defensive acquisitions less relevant. We agree that other takeover defenses can be important. One reason for our focus on defensive acquisitions is that other takeover defenses are limited in their effectiveness. For example, Ambrose and Megginson (1992) find that the only common takeover defense that is significantly negatively correlated with acquisition likelihood is blank-check preferred stock authorizations. Comment and Schwert (1995) conclude that "poison pill rights issues, control share laws, and business combination laws have not systematically deterred takeovers and are unlikely to have caused the demise of the 1980s market for corporate control...Antitakeover measures increase the bargaining position of target firms, but they do not prevent many transactions.” (p.3). See also Jensen and Ruback (1983), Jarrell, Brickley and Netter (1988), and Ruback (1988) for earlier surveys of the evidence on takeover defenses. Also see Schwert (2000).
} 
premium over its stand alone value. ${ }^{15}$

Finally, we determine the price at which a firm can acquire another firm in the following way: If Firm A acquires Firm B, it pays a premium above the stand alone value of Firm B such that Firm A's manager retains one half of his utility gain that arises from the acquisition if the premium were zero. Put differently, the premium is determined such that one half of the difference between the utility of Firm A's manager if he acquires Firm B at a zero premium and his utility if he does not acquire Firm B but subsequently behaves optimally (perhaps acquiring Firm $\mathrm{B}$ at a later point of time) accrues to Firm A's manager. For example, suppose Firm 1 acquires Firm 2 in the good state at date 1 . Because Firm 2 is worth $2 C_{2}$ if combined with Firm 1 but Firm 1 pays only $C_{2}$ for it if there is no premium, Firm 1 gains $C_{2}$ and its manager gains $\alpha C_{2}$. If Firm 1 pays $C_{2}+0.5 \frac{1}{\alpha} \alpha C_{2}=1.5 C_{2}$ for Firm 2, Firm 1's manager gains $0.5 \alpha C_{2}$ from the acquisition, which is half of what he would gain without paying a premium. We will use this price below. Of course, the premium above stand-alone value has to be nonnegative. Otherwise, Firm B's shareholders will not agree to the acquisition. Given these assumptions, an acquisition occurs whenever it is in the interest of the acquirer's manager if he offers at least a zero premium over the target's stand alone value.

\section{B. Equilibrium Merger Activity}

To find the equilibrium pattern of mergers, we solve the model by backwards induction, starting at date $1 .^{16}$ If the realized state of nature at date 1 is bad, all acquisitions are unprofitable. Firm 1 will not acquire Firm 2 or Firm 3 since the acquisition destroys value but Firm 1 has to pay at least the stand-alone value of the target firm. Hence, if Firm 1 were to make an acquisition, it would overpay. Moreover, Firm 1 does not need to defend itself against a potential acquisition since it is the largest firm. Since Firm 1 will not acquire Firm 2, there is no defensive motive for Firm 2 either, and hence, Firm 2 will not acquire Firm 3.

If the state at date 1 is good, Firm 1 has profitable acquisition opportunities. It will acquire the largest remaining firm, Firm 2, if Firm 2 has not acquired Firm 3 before. Firm 1 will make an acquisition because it is profitable to do so and because Firm 1 does not forgo a premium in case it is acquired - by assumption no firm can acquire Firm 1 since it is the largest firm. Moreover,

\footnotetext{
${ }^{15}$ This assumption simplifies the analysis considerably, because we do not have to analyze whether the target firm is interested in rejecting an offer in the hope of a better offer by the same firm or another firm later on. We conjecture that our main results are robust to relaxing this assumption.

${ }^{16}$ The unique subgame perfect equilibrium outcome can be found by backwards induction, because our
} 
Firm 1 will acquire the largest possible firm because its gains from the merger are increasing in the size of the target. If Firm 1 acquires Firm 2, its manager gains up to $\alpha \mathrm{C}_{2}$. Hence, he pays $\mathrm{C}_{2}+0.5 \frac{1}{\alpha} \alpha \mathrm{C}_{2}$ for Firm 2, i.e., a premium over Firm 2's stand-alone value of $0.5 \mathrm{C}_{2}$. Firm 2, because it is acquired by Firm 1, does not get to make an acquisition offer.

Now let us turn to date 0. Firm 2 may acquire Firm 3. While this merger reduces shareholder value, Firm 2's manager may want to acquire Firm 3 since this ensures that he keeps his job at date 1. If Firm 2 acquires Firm 3 at date 0 and pays a zero premium, the utility of Firm 2's manager is $2 \mathrm{w}-\alpha(1-\rho) \mathrm{C}_{3}$. The manager is employed in both dates, so he gets total private benefits of $2 w$. The merger with Firm 3 generates no synergies in the good state at date 1, but destroys $C_{3}$ in value in the bad state. Since the manager owns a share $\alpha$ of Firm 2 and because the bad state occurs with probability $1-\rho$, the manager has an expected utility loss of $\alpha(1-\rho) C_{3}$. If Firm 2 does not acquire Firm 3 at date 0 , it will be acquired by Firm 1 in the good state at date 1, as seen above. Hence, the expected payoff of Firm 2's manager if he does not acquire Firm 3 at date 0 is $w+(1-\rho) w+\rho 0.5 \alpha C_{2}$, equal to the wage at date 0 and in the bad state at date 1 plus the premium paid to the manager as a part owner of the firm when it is acquired by Firm 1 in the good state at date 1 . It can be calculated that Firm 2 chooses to acquire Firm 3 at date 0 if and only if:

(2) $\mathrm{w}>0.5 \alpha \mathrm{C}_{2}+\alpha \frac{1-\rho}{\rho} \mathrm{C}_{3}$.

Firm 1 never acquires another firm at date 0 . Such an acquisition will be unprofitable. Even if it paid a zero premium over Firm 2's stand alone value, the expected payoff of Firm 1's manager will be only $2 \mathrm{w}-(1-\rho) \alpha \mathrm{C}_{2}+\rho \alpha \mathrm{C}_{2}$ if Firm 1 acquired Firm 2 . This is lower than the payoff to Firm 1's manager if Firm 1 did not acquire Firm 2, because of (1). The same argument shows that Firm 1 would not acquire Firm 3 at date $0 .{ }^{17}$

Proposition 1 summarizes the above discussion and describes the equilibrium merger activity

model is a game of complete and perfect information.

${ }^{17}$ Note also that there is no incentive for Firm 1 to acquire any other firm in order to improve its acquisition opportunities at date 1 since we have assumed that each firm can make only one acquisition. For example, Firm 1 may want to acquire Firm 3 at date 0 although this is unprofitable because it ensures that Firm 2 will be available as a target at date 1 . However, because Firm 1 can only acquire one firm, it is never interested in acquiring Firm 3 at date 0 in order to make sure that it can acquire Firm 2 at date 1 . The simplifying assumption that each firm can make only one acquisition is discussed in more detail in section $\mathrm{V}$, where we conjecture what would happen if we relaxed this assumption. 
for all parameter regions:

Proposition 1: If private benefits are low enough so that (2) does not hold, Firm 1 acquires Firm 2 in the good state at date 1 in a profitable acquisition. If private benefits are high enough so that (2) holds, Firm 2 acquires Firm 3 at date 0 in an unprofitable acquisition.

Hence, for low private benefits, there is only the profitable (positive NPV) acquisition of Firm 2 by Firm 1. It is profitable because there are positive synergies (Firm 2 is worth more if combined with Firm 1) and Firm 1 appropriates some of this gain. For high private benefits, Firm 2 acquires Firm 3 in an unprofitable (negative NPV) acquisition at date 0.

The comparative statics on Firm 2's merger decision at date 0 illustrate the trade-offs its manager faces. They are summarized in Corollary 1:

Corollary 1: The minimum private benefits for the manager of Firm 2 such that the manager wants to acquire Firm 3 at date 0 increase in $C_{2}, C_{3}$, and $\alpha$ and decrease in $\rho$.

Proof: This can be easily seen from condition (2).

For given private benefits, Firm 2 is less likely to acquire Firm 3 at date 0 if $C_{2}$ is larger, because then Firm 2's manager forgoes a larger premium by acquiring Firm 3 rather than being acquired by Firm 1. This acquisition is also less likely if $C_{3}$ is larger, because then Firm 2's acquisition of Firm 3 destroys more value in the bad state at date 1. But this leads to a loss in shareholder value for Firm 2, because it has to pay at least a zero premium over Firm 3's stand-alone value. Firm 2 is less likely to acquire Firm 3 if $\alpha$ is larger, because then Firm 2's manager cares more about firm value, which is higher if Firm 2 forgoes the acquisition of Firm 3, because it is an unprofitable acquisition and moreover eliminates the premium Firm 2 can earn by being acquired by Firm $1 .^{18}$

Perhaps most importantly, if the probability of the good state at date 1 is higher, the date 0 acquisition is more attractive and hence the minimal private benefits that induce the manager to

\footnotetext{
${ }^{18}$ Consistent with our prediction, Lewellen, Loderer, and Rosenfeld (1985) find that managerial stock ownership has a positive impact on the quality of acquisitions managers make. Agrawal and Mandelker (1987) find that the smaller is the ownership stake of top managers (in the form of shares and options), the more likely are any mergers or sell-offs undertaken to reduce the variance of returns on the firm's assets or to reduce its leverage - goals that are in the managers', but not the shareholders' interests.
} 
engage in the date 0 acquisition are smaller. This implies that defensive mergers are more likely after a regime shift that increases the likelihood that future mergers are efficient. There are two reasons for this result. First, a date 0 acquisition becomes more attractive if the probability that such an acquisition turns out to not destroy value (the probability of the good state) increases. Second, if the probability of the good state is higher, there is a higher chance that Firm 2 will be acquired by Firm 1 if Firm 2 does not acquire Firm 3 at date 0. But since Firm 2's manager wants to avoid being acquired, he is more likely to be interested in acquiring Firm 3 at date 0 if his firm is more likely to be acquired otherwise.

Note that if Firm 2 acquires Firm 3, it will pay $\mathrm{C}_{3}+0.5 \frac{1}{\alpha}\left(2 \mathrm{w}-\alpha(1-\rho) \mathrm{C}_{3}-\mathrm{w}-(1-\rho) \mathrm{w}-0.5 \rho \alpha \mathrm{C}_{2}\right)$. Hence, Firm 2 pays more than Firm 3's stand alone value, although the combined value of the two companies is reduced due to negative expected synergies.

The following Corollary is clear:

Corollary 2: If private benefits are high enough so that (2) holds, then there are more acquisitions than would occur in the absence of private benefits. While a profitable acquisition could occur at date 1 , no profitable acquisitions occur. The only acquisition that occurs is unprofitable.

Thus, managerial self-interest leads to inefficient merger decisions. Managers make defensive mergers that protect their jobs at the expense of their shareholders. They may do so even if, as in our model, the expected synergies of the merger are negative. We refer to these mergers as “eat-or-be-eaten” mergers. Not only are the acquisitions unprofitable, but there are more mergers than occur in the first-best world (with no managerial merger motives). This is because managers do not just acquire when they know the alternative is to be acquired, but they also acquire even if there is a significant chance of being acquired in the future. In our model, the expected number of efficient mergers is $\rho$, while the actual number for sufficiently high private benefits is one.

It should be noted that a crucial element of the model is that, at some point, acquisitions can be profitable for Firm 1, namely, in the good state at date 1. However, a profitable acquisition may be preempted by an unprofitable, defensive acquisition. The only reason why these defensive mergers occur is the existence of efficient mergers. The positive synergies arising from combining Firm 1 with Firm 2 or 3 make it possible for Firm 1 to gain from an acquisition. However, if Firm 1 had no profitable acquisition opportunity at date 1, Firm 2 would never engage in a de- 
fensive acquisition. Since Firm 1 would never acquire it, there would be no reason for Firm 2 to defend its independence through a defensive acquisition. This is formalized in Corollary 3 :

Corollary 3: If there were no gains from mergers involving Firm 1 in the good state at date 1, Firm 2 would not acquire Firm 3 unless it was profitable to do so.

Finally, the premium over stand alone value that is paid by Firm 2 in the date 0 acquisition of Firm 3 can be higher than the premium over stand alone value that Firm 1 pays for Firm 2 in the good state at date 1 , although the latter is an efficient, value-creating merger while the former is value-destroying. The reason is that when Firm 2 acquires Firm 3, Firm 3 extracts some of the private benefits that Firm 2's manager preserves through the acquisition. However, the premium that Firm 1 pays for Firm 2 does not involve any private benefits, since the merger is not motivated by the preservation of any private benefits. Hence, if private benefits are sufficiently high, the inefficient acquisition of Firm 3 by Firm 2 can be associated with a higher premium. This is formalized in Corollary 4. Its proof as well as the proofs of all subsequent results can be found in the Appendix.

Corollary 4: If private benefits $w$ are high enough, the premium over stand alone value that Firm 2 pays for acquiring Firm 3 at date 0 is larger than the premium over stand alone value that Firm 1 pays for acquiring Firm 2 in the good state at date 1.

\section{Merger Waves}

In this section, we show how defensive motivations can lead to merger waves. For this, we expand the basic model in the previous section to five firms.

\section{A. The Extended Model}

The model is as in section I, but for the following changes: There are five firms, ordered by their sizes (stand alone values) $\mathrm{C}_{1}>\mathrm{C}_{2}>\mathrm{C}_{3}>\mathrm{C}_{4}>\mathrm{C}_{5}$. Again, only Firm 1 has a profitable acquisition opportunity in the good state at date 1. If Firm $j$ is combined with Firm 1, its value is $2 C_{j}$, i.e., there are positive synergies. All other combinations lead to neither positive nor negative synergies if the good state occurs at date 1: If Firm $i$ merges with Firm $j$, the value of the combined company is simply the sum of the stand-alone values, $C_{i}+C_{j}$. We assume that only one

firm has profitable acquisition opportunities (arising from positive synergies) to show that even if 
this is the case, our model can generate more than one merger. We assume that Firm 1 is the firm with the profitable acquisition opportunity, because this generates defensive merger motives for all other firms. Since firms that are larger than the largest firm with a profitable acquisition opportunity never participate in any merger, we can ignore such firms. Hence, giving Firm 1 the profitable acquisition opportunity is without loss of generality. As before, we assume that in the bad state at date 1 , mergers destroy value. In particular, we make the assumption that any firm that is acquired is worth zero in the bad state at date 1 .

Each firm can at each date make only one acquisition offer to another firm. We assume that all firms are sufficiently close in size such that the acquisition of any other firm makes each firm larger than Firm 1: $C_{4}+C_{5}>C_{1}$. We will also refer to this industry as a homogenous firm size industry. Below we develop a model with a very different size distribution. We also assume that if a firm is indifferent between acquiring two firms, it resolves this indifference in favor of acquiring the smaller of the two firms. Finally, we assume that within each period, Firm 4 moves first, Firm 3 second, Firm 2 third, and Firm 1 last (Firm 5 has no strategic decisions to make). We reverse the order of moves relative to the three firm model in the previous section, because this makes the intuition behind merger waves richer. However, if we assumed the opposite (original) order of moves, we would get similar results - and in particular, we would also get defensive merger waves.

We define a merger wave to be an outcome in which more than one merger takes place. Of course, in a model with five firms, there can be a maximum of two mergers. Figure 2 shows the sequence of events.

\section{B. Analysis}

We solve the model by backwards induction starting at date 1 . We give intuitive and informal arguments in the main text. Complete proofs can be found in the Appendix. In the bad state, there are no acquisitions. In particular, Firm 1 does not acquire any other firm. Anticipating this, Firm 2's manager is safe from an acquisition and does not need to acquire another firm to avoid being acquired. Hence, he makes his decision based on the profitability of the acquisition. Since all potential acquisitions are unprofitable, he does not acquire another firm. Firm 3's manager faces a similar situation. The only reason he would acquire another firm is to avoid being ac-

quired. But since neither Firm 1 nor Firm 2 will acquire another firm, there is no reason for him to be concerned about being acquired. The same reasoning applies to Firm 4's manager.

Next we turn to what happens in the good state at date 1 . The last firm to move is Firm 1. It will acquire the largest firm that has not already been involved in a merger, since the synergies 
are increasing in the target firm's size. Firm 1 will pay a premium over the stand-alone value of $0.5 C_{j}$ if it acquires Firm $j$, as in the three firm model. Anticipating that Firm 2 will be acquired by Firm 1 unless it makes an acquisition itself, Firm 2's manager, to preserve his second period private benefit $w$, wants to acquire Firm 5 if and only if:

(3) $\mathrm{w}>0.5 \alpha \mathrm{C}_{2}$.

Note that Firm 2 is indifferent between acquiring Firm 3, 4, and 5, and by assumption resolves this indifference in favor of acquiring the smallest firm.

Firm 3 knows that if (3) is satisfied, Firm 2 will acquire Firm 5 when it gets to move, leaving Firm 3 as the largest remaining firm that Firm 1 can acquire. To prevent this, it acquires the smallest firm it can if and only if (3) holds. Similarly, Firm 4 wants to acquire Firm 5 if and only if (3) holds. Since Firm 4 moves first, it gets to acquire Firm 5. After this, Firm 3 has no smaller firm to acquire. Thus, Firm 2 gets to retain its independence by acquiring Firm 3. Lemma 1 summarizes the resulting merger dynamics at date 1 .

Lemma 1: Suppose there have been no acquisitions at date 0 . Then, in the bad state at date 1, there are no acquisitions. In the good state at date 1, Firm 4 acquires Firm 5 and then Firm 2 acquires Firm 3 if (3) holds. If (3) does not hold, Firm 1 acquires Firm 2.

Now we turn to date 0 . We continue solving the model by backwards induction. Firm 1 will not make an acquisition at date 0 , because it is unprofitable to do so. Firm 2, however, may want to make an acquisition even though it is unprofitable in order to secure its independence in period 1. If Firm 2 acquires any firm, it will acquire the smallest firm possible, since this is the cheapest way to become larger than Firm 1 (recall that we assumed that $C_{4}+C_{5}>C_{1}$ ). This is also true for defensive acquisitions by Firms 3 and 4, so that all firms are potentially competing to acquire Firm 5. If Firm 2 acquires Firm 5 at date 0, its manager receives an expected payoff of up to (if a zero premium is paid) $2 \mathrm{w}-\alpha(1-\rho) \mathrm{C}_{5}$. If Firm 2 does not acquire Firm 5, Firm 4 is the next to move and will acquire Firm 5 in the good state at date 1 if and only if (3) holds. Firm 2 can then acquire Firm 3 in the good state at date 1 to secure its independence. Its manager's expected payoff at date 0 in this case is $2 \mathrm{w}-\rho 0.5\left(\mathrm{w}-0.5 \alpha \mathrm{C}_{2}\right)$, because Firm 2 pays a premium over the stand alone value of Firm 3 of $0.5 \frac{1}{\alpha}\left(\mathrm{w}-0.5 \alpha \mathrm{C}_{2}\right)$ in the good state at date 1 . This price ensures that Firm 2's manager keeps half of the utility gain that he would derive from acquiring Firm 3 at 
date 1 at a zero premium. It can easily be seen that, as a consequence, Firm 2 acquires Firm 5 at date 0 if and only if:

(4) $\mathrm{w}>0.5 \alpha \mathrm{C}_{2}+2 \alpha \frac{1-\rho}{\rho} \mathrm{C}_{5}$.

Similarly, it can be calculated that Firm 3 acquires Firm 5 and Firm 4 acquires Firm 5 if and only if:

(5) $\mathrm{w}>\max \left\{0.5 \alpha \mathrm{C}_{2}, 2 \alpha \frac{1-\rho}{\rho} \mathrm{C}_{5}-0.5 \alpha \mathrm{C}_{2}\right\}$.

Proposition 2 summarizes the merger activity for all parameter regions.

Proposition 2: If private benefits are low enough so that (3) does not hold, there is only one acquisition: Firm 1 acquires Firm 2 in the good state at date 1. This acquisition is profitable. If private benefits are high enough so that (3) holds, there are two acquisitions and both of them are unprofitable: Firm 4 acquires Firm 5 and Firm 2 acquires Firm 3. The date of the mergers depends on private benefit levels. For intermediate values of private benefits, Firm 4 acquires Firm 5 at date 0 or in the good state at date 1 and Firm 2 acquires Firm 3 in the good state at date 1 . For high values of private benefits, both of these acquisitions occur at date 0 .

The Proposition shows that if private benefits are low, the only merger is the most efficient one between Firm 1 and Firm 2. Both acquirer and target gain because Firm 1 pays a premium of $0.5 C_{2}$ over Firm 2's stand-alone value. No firm engages in a defensive acquisition because it is unprofitable and it also eliminates the chance of being taken over and hence earning a takeover premium. However, if managers care enough about their private benefits so that (3) is satisfied, the merger dynamics are drastically transformed from a world with only one profitable acquisition into a world with two defensive, unprofitable acquisitions. The efficient and profitable acquisition is preempted by two defensive, unprofitable acquisitions. For low enough private benefits, they may occur both in the good state at date 1 and hence are zero synergy mergers. Still, the acquirer overpays, and hence wealth is redistributed from the acquirer's shareholders to the target's shareholders (in exchange for control). However, for a high enough level of private benefits, both defensive acquisitions occur at date 0 . Our model gives rise to merger waves - two mergers either both at date 0 , both at date 1 , or one merger each at date 0 and date 1 .

The intuition behind the merger wave is as follows. If no merger has occurred yet, Firm 1 will acquire Firm 2 in the good state at date 1. Anticipating that, Firm 2 wants to acquire Firm 5 in the good state at date 1 . Anticipating that, Firms 3 and 4 also want to acquire Firm 5 in the 
good state at date 1 to avoid being the largest remaining firm except Firm 1 and hence the most attractive target for Firm 1. But Firm 2 anticipates that and wants to preempt them by acquiring Firm 5 at date $0^{19}$, and so do Firm 3 and Firm $4 .{ }^{20}$ After Firm 4 has acquired Firm 5, Firm 2 can only secure its independence by acquiring Firm 3.

We also see from Proposition 2 that the mergers tend to occur earlier if private benefits are higher. In our model, this also means that the synergies are lower and hence total value destruction for the acquirer and the target combined is higher, because date 1 acquisitions by firms other than Firm 1 have zero synergies while date 0 mergers are characterized by negative synergies. Higher private benefits make the managers more desperate and lead them to make defensive acquisitions earlier when they are even more costly to their shareholders. In particular, for high enough private benefits, managers do not wait until the good state of the world is realized at date 1 , but make defensive acquisitions before the state of the world is realized.

Even after Firm 4 has acquired Firm 5 at date 0, Firm 2 prefers acquiring Firm 3 at date 0 rather than at date 1 for high enough private benefits. The reason is that if Firm 2 acquires Firm 3 at date 1 , this is its last chance to secure its independence. Firm 3 understands that and extracts part of the private benefits for itself in the form of a high takeover premium. If Firm 2 acquires Firm 3 at date 0, the only surplus that Firm 3 can extract from Firm 2 is the difference between its manager's utility if he acquires Firm 3 at date 0 as compared to date 1 . Since both acquisitions secure Firm 2's independence, Firm 3 cannot extract the private benefits in a date 0 acquisition.

The results from the basic model in Section I are also confirmed. Namely, if the private benefits of control are large enough, there are too many mergers as compared to the efficient scenario, and they often come too early. Moreover, a regime shift that increases the chances for profitable acquisitions may turn out to induce unprofitable defensive and preemptive acquisitions, preventing profitable acquisitions from occurring.

\section{A Model with a Dominant Firm}

In the previous section we analyzed the merger dynamics in a situation in which all firms were of similar size so that even if the smallest two of the five firms merged, they became larger than the largest firm. In this section, we turn to a very different industry structure - one in which the largest firm is much larger than all the other firms. We show that in this case the merger dy-

\footnotetext{
${ }^{19}$ If it did not acquire Firm 5 and Firm 4 acquired Firm 5 in the good state at date 1, Firm 2 could still acquire Firm 3 in the good state at date 1, but that turns out to be less attractive than acquiring Firm 5 at date 0 .

${ }^{20}$ If Firm 3 did not acquire Firm 5, it could still acquire Firm 4 after Firm 2 acquired Firm 5, but this turns out to be less attractive.
} 
namics are very different. This illustrates that the industry structure - the distribution of firm sizes in the industry - is a crucial determinant of merger dynamics.

\section{A. The Model}

The model is as in the previous section, but for the following differences. There are only four firms, with sizes $C_{1}>C_{2}>C_{3}>C_{4}$. We present again the simplest model that generates the basic insights. For this purpose, a model with four firms suffices. The order of moves is as in the basic model with three firms, with firms moving in the order of size. So, at each date, Firm 1 moves first, Firm 2 second, and Firm 3 last (since Firm 4 has no strategic decision to make). Firm 1 is much larger than the other firms, in particular, larger than the combination of Firm 2 and Firm 3: $C_{1}>C_{2}+C_{3}$. We later refer to this industry as one with a heterogeneous firm size. Firm 3 and Firm 4 are, if combined, larger than Firm 2: $C_{3}+C_{4}>C_{2}$. Finally, as in the previous two models, the only firm that has positive synergies with other firms is Firm 1 in the good state at date 1 . If firm $j$ is combined with Firm 1 , it is worth $2 C_{j}$. If any firms other than Firm 1 combine in the good state at date 1 , their combined value is equal to the sum of their stand-alone values. In the bad state of the world, all mergers lead to negative synergies, and for simplicity we again assume that if Firm $i$ acquires Firm $j$, Firm $j$ is worth zero.

\section{B. Analysis}

As earlier, we solve the model by backwards induction. In the bad state at date 1 , there is no acquisition. Firm 1 will not acquire any other firm, and no other firm has an incentive to make an acquisition either. In the good state at date 1, Firm 1 acquires the largest remaining firm. If no acquisition has yet occurred, Firm 1 acquires Firm 2. Firm 3 has no reason to acquire Firm 4 afterwards, and hence remains passive.

Now we turn to date 0 . The last firm to move at that date that could make an acquisition is Firm 3. If Firm 3 acquires Firm 4, it becomes the second largest firm, since we have assumed $\mathrm{C}_{3}+\mathrm{C}_{4}>\mathrm{C}_{2}$. Acquiring Firm 4 is not sufficient to prevent it from being acquired by Firm 1 -

quite to the contrary, it makes Firm 3 the most attractive target for Firm 1, which will acquire Firm 3 in the good state at date 1 after Firm 3 has acquired Firm 4 . Firm 1 will pay a price of $\mathrm{C}_{3}+\mathrm{C}_{4}+0.5\left(\mathrm{C}_{3}+\mathrm{C}_{4}\right)$ for the combined firm. Hence, Firm 3's manager receives an expected payoff at date 0 of $w+(1-\rho)\left(w-\alpha C_{4}\right)+\rho \alpha 0.5\left(C_{3}+C_{4}\right)$ if Firm 3 acquires Firm 4. If Firm 3 does not acquire Firm 4, Firm 2 remains the second largest firm and hence Firm 1 acquires Firm 2 
in the good state at date 1. As a consequence, Firm 3's manager receives a payoff of $2 \mathrm{w}$. Hence, Firm 3 acquires Firm 4 if and only if $w+(1-\rho)\left(w-\alpha C_{4}\right)+\rho \alpha 0.5\left(C_{3}+C_{4}\right)>2 w$ or:

(6) $\mathrm{w}<0.5 \alpha\left(\mathrm{C}_{3}+\mathrm{C}_{4}\right)-\alpha \frac{1-\rho}{\rho} \mathrm{C}_{4}$.

Firm 2 moves before Firm 3 at date 0. If Firm 2 acquires Firm 4 at date 0, it ensures that it is the second largest firm and will be acquired by Firm 1 in the good state at date 1. Firm 1 will pay a price of $\mathrm{C}_{2}+\mathrm{C}_{4}+0.5\left(\mathrm{C}_{2}+\mathrm{C}_{4}\right)$ for the combined firm. Hence, Firm 2's manager receives an expected payoff at date 0 of up to $\mathrm{w}+(1-\rho)\left(\mathrm{w}-\alpha \mathrm{C}_{4}\right)+\rho \alpha 0.5\left(\mathrm{C}_{2}+\mathrm{C}_{4}\right)$ if Firm 2 acquires Firm 4. If Firm 2 does not acquire Firm 4, two situations can arise. If (6) holds, Firm 3 will acquire Firm 4, making it the second largest firm. In this case, Firm 1 will acquire the combination of Firms 3 and 4 and Firm 2 will remain independent. Hence, Firm 2's manager receives a payoff of $2 \mathrm{w}$. As a consequence, Firm 2 acquires Firm 4 if and only if $\mathrm{w}+(1-\rho)\left(\mathrm{w}-\alpha \mathrm{C}_{4}\right)+\rho \alpha 0.5\left(\mathrm{C}_{2}+\mathrm{C}_{4}\right)>2 \mathrm{w}$. One can easily show that this implies that Firm 2 acquires Firm 4 whenever (6) holds.

If (6) does not hold, Firm 3 will remain passive and not acquire Firm 4 if Firm 2 does not acquire Firm 4. In this case, Firm 2 remains the second largest firm and will be acquired by Firm 1 for a price of $C_{2}+0.5 C_{2}$ in the good state at date 1 . Hence, Firm 2's manager receives an expected payoff at date 0 of $w+(1-\rho) w+\rho \alpha 0.5 C_{2}$. Given this, Firm 2 will never acquire Firm 4 if (6) does not hold. Hence, Firm 2 acquires Firm 4 if and only if (6) holds. One can also show that Firm 2 always prefers to acquire Firm 4 to acquiring Firm 3. Proposition 3 summarizes the equilibrium merger dynamics.

Proposition 3: If private benefits are low enough so that (6) holds, there are two profitable acquisitions: Firm 2 acquires Firm 4 at date 0. Then Firm 1 acquires the combination of Firm 2 and Firm 4 in the good state at date 1 . If private benefits are high enough so that (6) does not hold, there is one profitable acquisition: Firm 1 acquires Firm 2 in the good state at date 1.

The Proposition shows that again the size of the private benefits determines merger activity. However, in contrast to the previous models, the relationship between private benefits and the number of mergers is reversed. In particular, there are two mergers (one early one at date 0 ) if private benefits are low enough and there is only one merger if private benefits are sufficiently high. The early acquisition of Firm 4 by Firm 2 is not defensive. Quite to the contrary, Firm 2 acquires Firm 4 in order to ensure that it is the most attractive target - because it is the largest 
potential target firm - for Firm 1 in the good state at date 1. If it would not acquire Firm 4, Firm 3 would do so and become the second largest firm and hence the most attractive takeover target for Firm 1. In this model, acquisitions cannot have defensive value, because no firm can become larger than Firm 1 through acquisitions. Instead, firms make acquisitions in order to become the second largest firm or remain the second largest firm so that they are the most attractive target for Firm 1 and earn a takeover premium. We will also refer to such acquisitions below as "positioning” mergers. Of course, managers engage in these acquisitions to make their firms more attractive targets only if they care sufficiently strongly about firm value and less about the private benefits of control. This explains why they engage in acquisitions if private benefits are low but avoid acquisitions if private benefits are high.

It should be noted that the date 0 acquisition of Firm 4 by Firm 2 - in contrast to the date 0 acquisitions in the previous models - is a positive NPV acquisition for Firm 2. Firm 2 engages in this acquisition only if the takeover premium its manager can earn $\left(0.5 \rho\left(C_{2}+C_{4}\right)\right)$ is worth more than the expected loss in firm value that arises due to the negative synergies in the bad state of the world $\left((1-\rho) C_{4}\right)$. This is implied by condition (6), as can be seen after some algebraic manipulation.

More generally, this model with a dominant firm makes the point that the industry structure - the distribution of firm sizes in an industry - is a key driver for merger dynamics.

\section{A Model of an Industry in which Some But Not All Firms Are of Similar Size}

In Section II, we presented a model in which all firms were of similar size. Even if Firm 4 acquired Firm 5, it became larger than Firm 1. Hence, all acquisitions had defensive value. In section III, we presented a model in which the largest firm was much larger than all other firms. Even if Firm 2 acquired Firm 3, it was still smaller than Firm 1. Hence, no acquisition could have defensive value. Both of the models were extreme in the sense that either all acquisitions have defensive value or none have defensive value. In this section, we present a model that is a compromise between the previous two models. We will also refer to this type of industry as a mixed firm size industry below. Analyzing this industry structure will allow us to generate implications of acquirer and target size for the profitability of acquisitions.

We assume that $\mathrm{C}_{2}+\mathrm{C}_{5}>\mathrm{C}_{1}, \mathrm{C}_{3}+\mathrm{C}_{4}>\mathrm{C}_{1}, \mathrm{C}_{3}+\mathrm{C}_{5}<\mathrm{C}_{1}$, and $\mathrm{C}_{4}+\mathrm{C}_{5}>\mathrm{C}_{2}$. At each date, Firm 4 moves first, Firm 3 second, Firm 2 third, and Firm 1 last. The remainder of the model is as before. 
Proposition 4 describes the equilibrium merger dynamics. For brevity, we will focus on one particular parameter region. The results in the other parameter regions are almost identical.

Proposition 4: Suppose that (i) $-4 \alpha \frac{1-\rho}{\rho} C_{5}+\alpha\left(C_{4}+C_{5}\right)+0.5 \alpha C_{3} \leq 0.5 \alpha\left(C_{3}+C_{5}\right)$;

(ii) $0.5 \alpha C_{3}+\alpha\left(C_{4}+C_{5}\right)<0.5 \alpha C_{2}+2 \alpha \frac{1-\rho}{\rho} C_{5}$; and

(iii) $0.5 \alpha \mathrm{C}_{2}+2 \alpha \frac{1-\rho}{\rho} \mathrm{C}_{5}<0.5 \alpha \mathrm{C}_{3}+2 \alpha \frac{1-\rho}{\rho} \mathrm{C}_{4}$. Then there exists $w_{i}, i \in\{1, \ldots, 7\}$ such that the following mergers occur in equilibrium:

- If private benefits are low enough ( $w<w_{1}$ ), then there are two profitable acquisitions: Firm 4 acquires Firm 5 at date 0 and Firm 1 acquires the combination of Firms 4 and 5 in the good state at date 1.

- If $w \in\left[w_{1}, w_{2}\right)$, Firm 3 acquires Firm 5 at date 0 and Firm 1 acquires the combination of Firms 3 and 5 in the good state at date 1. Both acquisitions are profitable.

- If $w \in\left[w_{2}, w_{3}\right)$, Firm 4 acquires Firm 5 in the good state at date 1 and Firm 1 acquires the combination of Firms 4 and 5 in the good state at date 1. Both acquisitions are profitable.

- If $w \in\left[w_{3}, w_{4}\right]$, Firm 3 acquires Firm 5 in the good state at date 1 and Firm 1 acquires the combination of Firms 3 and 5 in the good state at date 1. Both acquisitions are profitable.

- If $w \in\left(w_{4}, w_{5}\right)$, Firm 4 acquires Firm 5 in the good state at date 1 and then Firm 1 acquires the combination of Firms 4 and 5 in the good state at date 1. Both acquisitions are profitable.

- If $w \in\left[w_{5}, w_{6}\right]$, Firm 3 acquires Firm 4 in the good state at date 1 and then Firm 2 acquires Firm 5 in the good state at date 1. Both acquisitions are unprofitable.

- If $w \in\left(w_{6}, w_{7}\right]$, Firm 2 acquires Firm 5 at date 0 . Then Firm 3 acquires Firm 4 in the good state at date 1 . Both acquisitions are unprofitable.

- If private benefits are high enough $\left(w>w_{7}\right)$, Firm 4 acquires Firm 5 at date 0. This acquisition is unprofitable for high enough private benefits. Then Firm 1 acquires the combination of Firms 4 and 5 in the good state at date 1. This acquisition is profitable.

There are various features of the equilibrium merger dynamics that should be noted. First, there are always two mergers, unlike in the previous models. Hence, an industry in which some, but not all firms are of similar size gives rise to the most mergers and is most likely to generate merger waves. In such an industry, some firms have defensive merger opportunities (in this 
model: Firm 3 can defend itself against an acquisition by Firm 1 by acquiring Firm 4, and Firm 2 can do so by acquiring any other firm) while other firms cannot defend themselves (Firm 4 cannot become large enough through an acquisition to avoid being acquired by Firm 1). If private benefits are low, firms without defensive merger opportunities (or firms that have the opportunity to engage in defensive as well as other acquisitions) want to acquire other firms to become larger and hence an attractive target for Firm 1. One of them eventually will be acquired by Firm 1 after having acquired another firm itself. On the other hand, if private benefits are high, firms with defensive merger opportunities want to acquire other firms to avoid being acquired. This prevents Firm 1 from acquiring any firm. Thus, for both low and high private benefits, two mergers occur.

One other interesting feature is that in this model Firm 3 has the choice between making a defensive acquisition (acquiring Firm 4) and making an acquisition to make it an attractive target for Firm 1 (by acquiring Firm 5). For low private benefits, Firm 3 acquires Firm 5 to become a more attractive target and hence earn a premium from Firm 1. For high private benefits, Firm 3 acquires Firm 4 to defend itself against being acquired by Firm 1. Hence, for a firm with the opportunity to engage in defensive as well as non-defensive acquisitions, the NPV of the acquisition is decreasing in the ratio of the target's to the acquirer's size. In particular, if Firm 3 acquires a small firm (Firm 5), it engages in a positive NPV acquisition. However, if Firm 3 acquires a large firm (Firm 4), it engages in a negative NPV acquisition. This is because the acquisition of Firm 4 has defensive value while the acquisition of Firm 5 does not.

In general, we see from all the models that there is a negative correlation between private benefits and the NPV of acquisitions (only for the dominant firm model is there no correlation). The more firms care about private benefits, the more likely they are to engage in defensive acquisitions and secure their independence by acquiring other firms even though this is unprofitable.

In the models in sections II and III, it happened to be the case that the first firm that could engage in an acquisition, given the exogenously specified order of moves, always engaged in the first merger if any firm other than Firm 1 made an acquisition. This result did not arise by assumption; a different order of moves would have been possible. However, in the model with a dominant firm (see section III), by assumption Firm 2 moved before Firm 3 and if it did not acquire Firm 4, Firm 3 would have done so and hence would have left Firm 2 a less attractive target. Hence, for low private benefits of control, Firm 2 acquired Firm 4. On the other hand, for high private benefits, Firm 2 did not want to acquire Firm 4 - but then Firm 3 did not either. Hence, whenever there was an acquisition at date 0, it was Firm 2 who was the acquirer.

In the model in Section II, Firm 4 moved before Firms 2 and 3. It also had the strongest incentive to engage in an (always defensive) acquisition, because it stood to gain the smallest pre- 
mium by being acquired by Firm 1 (since synergies were assumed to be proportional to size). Hence, Firm 4 always was the first firm to make an acquisition, if any firm other than Firm 1 made an acquisition.

In the model in this section, there is a greater flexibility in who acquires whom. Proposition 4 shows that all of the firms make an acquisition in some parameter region. The Proposition shows also that for higher private benefits, there is a tendency for larger firms to be the acquirer. ${ }^{21}$ In particular, Firm 2 makes acquisitions for high private benefits only. The Proposition also shows that large firms tend do negative NPV acquisitions, while small firms (Firm 4) tend do to positive NPV acquisitions. ${ }^{22}$ Moreover, the combination of acquirer and target size tends to be larger for high private benefits and hence in negative NPV acquisitions: if Firm 2 acquires Firm 5 or Firm 3 acquires Firm 4 - so that the combined company is larger than Firm $1{ }^{23}$ In contrast, for small private benefits, the acquirer tends to be smaller and the sum of acquirer and target size smaller than the size of Firm 1.

\section{Discussion of Assumptions and Model Features}

In this section, we discuss some of the assumptions and key model features, including implications on how to relate the model to the empirical evidence.

\section{A. Firm Size and the Anticipation of Mergers}

In our models, firm size is given by the stand-alone value of the firms. In principle, this should be interpreted as the equity value of the firms, since our firms are all-equity financed. For simplicity, we assume that the future mergers are not anticipated by the stock market although, in our simple model, it should already be clear at date 0 which acquisitions will take place (except that the state at date 1 is not yet realized). For example, consider the model with firms of similar firm size. If Firm 4 acquires Firm 5 at date 0, this acquisition should already be anticipated at the beginning of date 0 . This should be reflected in the stand-alone values of both Firm 4 and Firm 5 . In particular, Firm 4's value before the acquisition should be lower than $C_{4}$ because it will en-

\footnotetext{
${ }^{21}$ This is true with the exception of the highest private benefits, in which Firm 4 is the acquirer. In this parameter region, Firm 4 wants to acquire Firm 5 at date 0, because this saves its independence for one period - otherwise Firm 3 would acquire it at date 0.

${ }^{22}$ However, for very high private benefits, Firm 4 acquires Firm 5 in an unprofitable acquisition (see the previous footnote). While Firm 4 is too small to protect its independence for two periods, this acquisition secures its independence for one period, and Firm 4's manager is willing to overpay for Firm 5 for this reason.

${ }^{23}$ Again, the exception is the acquisition of Firm 5 by Firm 4 for very high private benefits. See the previous footnote.
} 
gage in a negative NPV acquisition. Firm 5's value should be higher than $C_{5}$ because it will earn a premium in the acquisition. We ignore this issue here and assume that the market does not anticipate the acquisitions, perhaps due to some unmodeled uncertainty. We view it as a feature of our simple model rather than reality that it should be possible to anticipate all mergers perfectly. The assumptions that allow mergers to be perfectly anticipated are made to simplify the exposition. We could relax them, for example, by making the order of moves random. Then, investors could not perfectly anticipate mergers, but the qualitative results would not change and our analysis would be much more complicated.

The (lack of) anticipation of the mergers is relevant for our model only because anticipating mergers can affect the size ordering of firms, which in turn can affect who can acquire whom. Coming back to the example above, Firm 4 may not be able to acquire Firm 5 since it may be smaller than Firm 5 due to the anticipated reduction in its value arising from the negative NPV acquisition and Firm 5's anticipated increase in firm value due to the takeover premium. This could affect the equilibrium merger activity.

We have checked the robustness of our results to these modeling issues for the three firm and the four firm model. In particular, we have analyzed a model in which the premium is as in the model we presented, but limited such that the acquirer is not smaller than the target once the merger is fully anticipated (however, the premium has to be still at least zero). In such a model, equilibrium merger activity may be affected by the anticipation of mergers because some negative expected synergies mergers may not occur because the acquirer would be smaller than the target (since the premium cannot be smaller than zero). Our results do not change once we adjust the assumptions on the stand alone values of the firms slightly. However, we have not been able to do the same robustness analysis for the two five firm models, since the models become exceedingly complicated once all mergers are anticipated.

In the empirical implications section below, we will assume that an (un)profitable acquisition leads to a positive (negative) acquirer announcement return. This is a reasonable interpretation if acquisitions are not perfectly anticipated, which seems to be a realistic assumption that also holds in our model.

\section{B. Intra- and Inter-Industry Mergers}

We interpret all mergers to be intra-industry mergers. The efficient merger opportunity in the good state at date 1 is meant to capture efficient merger opportunities after a regime shift within an industry. We believe that defensive mergers occur most plausibly within an industry and hence our model applies best to intra-industry mergers. A firm could in principle acquire another firm in 
a defensive acquisition outside its own industry. However, it is presumably much easier to justify such an acquisition before shareholders, institutional investors, and the financial press if management can appeal to the possibility of synergies, which is more plausible in intra-industry mergers. Acquiring another firm well outside one's industry may be too obviously a defensive move and might be not accepted by shareholders. Moreover, a defensive acquisition outside a firm's industry may be more costly (since it might create more negative synergies). Hence, we feel that the most likely targets for defensive mergers are firms in the same industry, where this industry could be broadly defined to include related industries. This is also true for positioning mergers. Intra-industry mergers are more likely to make a firm a more attractive takeover target for firms within its industry (that may receive an efficient merger opportunity), because synergies are more likely in intra-industry mergers.

\section{Only One Acquisition per Firm and the Role of the Largest Firm}

We assume throughout our analysis that each firm can only make one acquisition. Once a firm has made an acquisition, it cannot engage in another one. This assumption simplifies our analysis considerably. Consider the three firm model. If Firm 2 could engage in two acquisitions, it might acquire Firm 1 in the good state at date 1 after acquiring Firm 3 at date 0. Anticipating this, Firm 1 might want to protect its independence by acquiring Firm 3 at date 0. Such an acquisition would also ensure that Firm 2 would be available as a takeover target in the good state at date 1 . Hence, allowing multiple acquisitions per firm could create incentives for Firm 1 to engage in date 0 acquisitions (which may or may not be defensive). This would not affect the main insights from the model (the possibility of defensive mergers and when they occur) and indeed might make the three firm model more realistic (in having a less stylized role for the largest firm) and interesting. However, it would complicate the analysis. We conjecture that allowing only one acquisition per firm is less restrictive in the other models with four and five firms. As in the three firm model, the largest firm might have an incentive to engage in a date 0 acquisition. But there is no reason for it to do so in the four firm model since Firm 1 can even without a date 0 acquisition always acquire another firm in the good state at date 1 and benefits from mergers between the other firms since it prefers to acquire the largest possible firm. In the five firm models, Firm 1 might have an incentive to acquire another firm at date 0 to make sure that a target is still available in the good state at date 1 or to avoid being taken over itself by a firm that might grow larger than it through an acquisition, but by the time it moves this acquisition opportunity is unlikely to be still available. 
However, we do need a limit on the speed with which firms can make acquisitions. If firms could acquire other firms instantaneously and without transaction costs so that a firm could immediately become the largest firm in the industry through a wave of acquisitions, large firm size would not be a defense anymore and current firm size irrelevant. We believe that in reality transactions costs and also competition for targets make current firm size an important determinant of future firm size and hence current firm size matters for the probability of being taken over.

One other reason why the largest firm makes no defensive acquisitions is that we assume that it is absolutely impossible for a firm to acquire a larger firm. In a more general (and realistic) model, acquiring a larger firm would be more difficult but not impossible. Then the largest firm might also have to worry about becoming a takeover target. Its behavior in our model is so simple only because of the simplifying assumptions that make our model tractable. Hence, one should not draw any empirical implications from the behavior of the largest firm in our model.

\section{Empirical Implications}

As already discussed above, the theory developed in this paper can explain several stylized facts about mergers. These stylized facts include that abnormal returns to acquirers are on average negative, that mergers concentrate in industries in which there is an identifiable regime shift that may make mergers an efficient response, and that mergers come in waves. In this section, we discuss additional empirical implications of our theory.

A key assumption underlying our theory is that defensive acquisitions work in the sense that they make it less likely that the acquirer is taken over itself subsequently. Louis (2004) provides direct evidence for this in a study of the U.S. banking industry. He finds that banks that were takeover targets and then engaged in acquisitions are less likely to be acquired subsequently than targeted banks that do not make an acquisition. Our theory also predicts that these defensive acquisitions perform worse for the acquirer's shareholders than other acquisitions. This is again consistent with the evidence in Louis (2004). He finds that defensive acquisitions by banks (that is, acquisitions by banks that were the target of a takeover attempt themselves) are characterized by higher premia and the acquirers in such mergers experience worse (and significantly negative) abnormal returns than acquirers in nondefensive mergers.

Our theory suggests a number of factors that influence a firm's incentives to engage in defensive acquisitions. One such factor is linked to managerial incentives, which are determined by the manager's interest in private benefits on the one hand and maximizing shareholder wealth on the other hand. The manager cares about the latter because he owns a certain fraction of the firm's equity. If the manager is more interested in private benefits, defensive acquisitions are more 
likely. Hence, our theory predicts a negative correlation between measures of private benefits and acquirer announcement returns as well as a positive correlation between managerial equity ownership and announcement returns (see Propositions 1, 2, and 4). The only exception to that is that in heterogeneous firm size industries all acquisitions are profitable and hence there is no correlation between private benefits (or managerial equity stakes) and acquirer returns (see Proposition 3). Consistent with our general prediction, Lewellen, Loderer, and Rosenfeld (1985) find that managerial stock ownership is positively correlated with acquirer announcement returns.

The second factor affecting the defensive motivation of an acquisition is firm size. We predict a negative correlation between acquirer returns and acquirer size because large firms are more likely to engage in defensive acquisitions than small firms. ${ }^{24}$ More specifically, our theory implies that large firms tend to make negative NPV acquisitions (leading to negative abnormal returns), medium size firms both positive and negative NPV acquisitions, and small firms positive NPV acquisitions. This can be seen from Proposition 4, which applies to mixed firm size industries. In such industries, the only acquisitions that large firms undertake (with the exception of the largest firm) are of defensive nature, and they occur if private benefits are high (if private benefits are sufficiently low, they do not make any acquisitions). Small firms tend to undertake only positioning acquisitions that make them more attractive (since larger) takeover targets and hence are profitable. They occur if private benefits are low. ${ }^{25}$ Medium size firms sometimes undertake defensive acquisitions when they acquire relatively large companies if private benefits are high but also sometimes undertake profitable acquisitions if they acquire smaller firms to make themselves more attractive takeover targets (the latter occurs if private benefits are low). These implications are consistent with the findings in Kahl and Rosen (2002), who find that acquirer returns are decreasing in acquirer size, and Moeller, Schlingemann, and Stulz (2004), who find that large acquirers have negative and small acquirers have positive announcement returns.

Another factor affecting defensive motivations in our theory is the size of the target or deal size. We predict a negative correlation between acquirer returns and target size, because larger acquisitions are more likely to be defensively motivated. This is true because a larger acquisition

\footnotetext{
${ }^{24}$ The notion of size in our model is relative size - size relative to the largest firm in the industry with profitable acquisition opportunities. In particular, large firms are firms that by acquiring any other firm become larger than the previously largest firm. Medium size firm are firms that can become the largest firm by acquiring another firm but that can remain smaller than the largest firm by acquiring another firm. Small firms are firms that cannot become larger than the largest firm by acquiring another firm (which, by assumption, has to be smaller than they are). In spelling out the empirical implications, we will talk about firm size in an absolute sense. This presumes that relative size in the sense of the model and absolute size are often highly correlated. This is a caveat for our empirical implications on firm size.

${ }^{25}$ The exception is the acquisition of Firm 5 by Firm 4 that occurs for very high private benefits and allows Firm 4 to remain independent for one period (see the earlier discussion of this exception).
} 
increases firm size more than a smaller acquisition, and being larger reduces the probability of being acquired. Hence, a larger acquisition has greater defensive value than a smaller acquisition and is typically done when private benefits are higher. In our model, large acquisitions tend to be negative NPV while small acquisitions tend to be positive NPV. This is consistent with the evidence in Kahl and Valkanov (2004), who find that acquirer returns are decreasing in the size of the merger transaction. This implication can be seen from Proposition 4, which applies to mixed firm size industries. There, acquisitions of Firm 4 are always unprofitable, while acquisitions of Firm 5 are, with one exception, always profitable.

As a consequence of the previous observations on acquirer size and target size, we also predict that the sum of acquirer and target size is positively correlated with private benefits and negatively correlated with acquirer returns.

Our theory also points to the importance of the relative size of the target and the acquirer for the motivation of the merger. The effect of relative size of target and acquirer depends on the size of the acquirer. In particular, Proposition 4 shows that for medium sized firms, the ratio of target to acquirer size is negatively correlated with acquirer returns. This arises because medium sized firms acquire relatively large firms for defensive purposes if private benefits are high but relatively small firms in positioning mergers if private benefits are low. In contrast, for small acquirers, we conjecture that the ratio of target to acquirer size and the acquirer's abnormal returns are positively correlated. This does not directly follow from our model, since the smallest firm in our model that can make an acquisition (Firm 4) has only one potential target (Firm 5). However, it is easy to see that in a more general model with a sixth firm, acquiring Firm 5 should be more profitable for Firm 4 than acquiring Firm 6, since it makes it a more attractive takeover target (and the premium is proportional to the firm's size).

Some of the implications discussed so far are also consistent with other managerial merger theories. For example, a negative correlation between acquirer returns and acquirer size could arise if one assumes that small firms suffer less from agency problems than large firms. A negative correlation between deal size and acquirer returns is also consistent with a general empirebuilding hypothesis that suggests that larger acquisitions are more likely to be driven by managerial empire-building. These managerial theories have difficulties explaining some of the other empirical findings mentioned above (for example the concentration of mergers in industries in which one can identify a regime shift that may make mergers efficient). In the following we will spell out some additional implications of our theory that may discriminate more strongly between our theory and other managerial theories. These predictions concern, among others, the role of 
industry structure, which is key to our theory but not important in other managerial theories, and the role of positioning mergers, which play no role in these theories.

Our model suggests which firms are most likely to acquire others. Our analysis shows that large firms are most likely to engage in acquisitions if private benefits are high and small firms if they are low (see Proposition 4). ${ }^{26}$ Medium size firms are the most likely to engage in acquisitions - they engage both in defensive as well as positioning acquisitions (see Proposition 4).

We argue that an important factor driving merger activity is the firm size distribution in an industry. In particular, we predict that homogenous firm size industries (or firms of similar size within an industry) are likely to be characterized by defensive merger waves rather than waves of positive NPV acquisitions and hence have the worst average abnormal returns for acquirers. Moreover, we expect merger waves in these industries only for high private benefits (see Proposition 2). In contrast, heterogeneous firm size industries (or firms of different size within an industry) are most likely to exhibit profitable acquisitions, even during merger waves. The merger waves should occur when private benefits are low (see Proposition 3). Mixed firm size industries are most likely to exhibit merger waves, because they occur both if private benefits are low and if they are high. We expect acquirers in these industries to perform, on average, better than acquirers in homogeneous firm size industries but worse than acquirers in heterogeneous firm size industries (see Proposition 4).

Managerial interest in private benefits also affects the timing of the mergers. We show that in homogenous firm size industries mergers tend to occur earlier if private benefits are higher perhaps before the regime shift that makes some mergers efficient. Managers are then more desperate to secure the independence of their firms and hence resort to defensive acquisitions earlier, which makes them more costly to their shareholders. Hence, we predict a negative correlation between private benefits and not only acquirer returns, but also combined acquirer and target returns (synergies) in homogenous firm size industries.

\section{Conclusion}

In this paper we have argued that managerial defensive motives are important for explaining merger decisions and merger dynamics. Managers may want to make acquisitions to increase their firm's size and hence reduce the likelihood that it is taken over. This may allow them to preserve their private benefits of control. If managers do not care very much about private benefits of control, only profitable acquisitions occur. However, if managers care very much about private benefits of control, they may engage in unprofitable defensive acquisitions that preempt some 
profitable acquisitions. These defensive merger motives are self-reinforcing and may generate a wave of defensive acquisitions. There are too many mergers and they come too early. As a consequence, a regime shift that may make some acquisitions profitable may lead to a wave of unprofitable defensive acquisitions.

We show that industry structure - the size distribution of the firms in the industry - is very important for merger dynamics. Industries in which many firms are similar in size to the largest firm with profitable acquisition opportunities are prone to defensive merger waves if managers care a lot about private benefits of control. However, industries in which firms are of very different size are less prone to waves of unprofitable acquisitions. In contrast, they may display merger waves of profitable acquisitions if managers do not care a lot about private benefits of control. In industries in which some but not all firms are of similar size, merger waves are most likely, because they occur if private benefits are either low or high. The profitability of acquisitions tends to decrease in the acquirer's size. Large acquirers overpay while small acquirers tend to engage in profitable acquisitions. Firms of intermediate size sometimes engage in profitable and sometimes in unprofitable acquisitions.

Our theory can explain why mergers are concentrated in industries for which a regime shift can be identified. At the same time, it can explain why acquirers lose money, on average, and why mergers often occur in waves. The theory generates some additional testable empirical implications. Some of these predictions are consistent with the available empirical evidence, such as the negative correlation between acquirer announcement returns and both acquirer size (Kahl and Rosen (2002) and Moeller, Schlingemann, and Stulz (2004)) and the size of the merger transaction (Kahl and Valkanov (2004)) as well as the worse acquirer returns in defensive acquisitions (Louis (2004)). We leave the testing of our other predictions to future empirical work. These predictions include that medium sized firms are the most likely to engage in acquisitions and that mixed firm size industries are the most prone to merger waves while homogenous firm size industries are characterized by the lowest average acquirer abnormal returns.

\footnotetext{
${ }^{26}$ The exception is again the acquisition of Firm 5 by Firm 4 if private benefits are very high.
} 


\section{Appendix: Proofs}

Proof of Corollary 4: If Firm 1 acquires Firm 2 in the good state at date 1, it pays $\mathrm{C}_{2}+0.5 \mathrm{C}_{2}$ and hence a premium over Firm 2's stand alone value of $0.5 \mathrm{C}_{2}$. If Firm 2 acquires Firm 3 at date 0 , its manager receives an expected payoff of up to $2 w-\alpha(1-\rho) C_{3}$. If Firm 2 does not acquire Firm 3 at date 0 , it is acquired by Firm 1 in the good state at date 1 for $\mathrm{C}_{2}+0.5 \mathrm{C}_{2}$ and hence its manager receives an expected payoff at date 0 of $\mathrm{w}+(1-\rho) \mathrm{w}+\rho \alpha 0 \cdot 5 \mathrm{C}_{2}$. As a consequence, if Firm 2 acquires Firm 3 at date 0 , it will pay $C_{3}$

plus $0.5 \frac{1}{\alpha}\left(2 \mathrm{w}-\alpha(1-\rho) \mathrm{C}_{3}-\mathrm{w}-(1-\rho) \mathrm{w}-\rho \alpha 0.5 \mathrm{C}_{2}\right)$ or $0.5 \frac{1}{\alpha}\left(\rho\left(\mathrm{w}-0.5 \alpha \mathrm{C}_{2}\right)-\alpha(1-\rho) \mathrm{C}_{3}\right)$ so that Firm 2's manager keeps one half of his utility gain from acquiring Firm 3 at a zero premium. Hence, the difference between the premium over stand-alone value at date 0 and the one at date 1 is $0.5 \frac{1}{\alpha}\left(\rho\left(w-0.5 \alpha C_{2}\right)-\alpha(1-\rho) C_{3}\right)-0.5 C_{2}$. This is positive for sufficiently high $w$.

Proof of Lemma 1: First consider the bad state at date 1. We solve the model by backwards induction. Firm 1 is the last firm to move. It does not acquire any other firm, because this would be unprofitable. If Firm 1 acquired Firm $j$, it would have to pay at least $C_{j}$. However, Firm $j$ would be worth only zero to Firm 1, due to the negative synergies. Firm 2 moves before Firm 1. Its manager knows that Firm 1 will not acquire it if it remains independent. Hence, Firm 2 has no defensive motive to make an acquisition. As a consequence, it makes an acquisition only if it is profitable. But all acquisitions are unprofitable. The argument is the same as the one given above for Firm 1. One can easily show that the same arguments imply that neither Firm 3 nor Firm 4 make an acquisition. We can summarize the merger activity in the bad state at date 1 as follows.

There are no acquisitions in the bad state at date 1.

Now consider the good state at date 1 . Firm 1 is the last to move. If Firm 1 acquires firm $j$, its manager gains $\alpha C_{j}$, because firm $j$ is worth $2 \mathrm{C}_{\mathrm{j}}$ if combined with Firm 1 . Because the utility gain for Firm 1 's manager is split evenly with Firm $j$, Firm 1 pays $C_{j}+0.5 C_{j}$, i.e., a pre- 
mium of $0.5 C_{j}$ over firm $j$ 's stand alone value. Firm 1's manager has a payoff of $w+0.5 \alpha C_{j}$, which is increasing in $C_{j}$. Hence, Firm 1 acquires Firm 2. Hence, we can summarize Firm 1's behavior as follows:

Firm 1 acquires Firm 2 in the good state at date 1.

Firm 2 moves before Firm 1. If Firm 2 acquires Firm 5, its manager gets a payoff of up to (if a zero premium is paid) $w$. If he does not acquire Firm 5, Firm 2 is acquired by Firm 1 and Firm 2's manager receives $0.5 \alpha C_{2}$. Hence, Firm 2 acquires Firm 5 if and only if $w>0.5 \alpha C_{2}$. It can be easily shown that the condition under which Firm 2 acquires Firm 4 or 5 is the same and that Firm 2's manager receives the same payoff regardless of which firm he acquires, $\mathrm{w}-0.5\left(\mathrm{w}-0.5 \alpha \mathrm{C}_{2}\right)$. By assumption, he resolves the indifference in favor of acquiring the smallest firm, Firm 5. We can summarize Firm 2's behavior as follows:

Firm 2 acquires Firm 5 in the good state at date 1 if and only if $\mathrm{w}>0.5 \alpha \mathrm{C}_{2}$.

Firm 3 moves before Firm 2. If Firm 3 acquires Firm 5, its manager receives up to $w$. If he does not acquire Firm 5, two situations can arise. If $\mathrm{w} \leq 0.5 \alpha \mathrm{C}_{2}$, Firm 2 will not acquire Firm 5 and then Firm 1 will acquire Firm 2. Hence, Firm 3 remains independent and its manager receives $w$. Hence, he does not acquire Firm 5. However, if $w>0.5 \alpha C_{2}$, Firm 2 will acquire Firm 5. Then Firm 3 is the largest remaining firm that can be and will be acquired by Firm 1. In this case, Firm 3's manager receives $0.5 \alpha \mathrm{C}_{3}$. Hence, Firm 3 acquires Firm 5 if and only if $w>0.5 \alpha \mathrm{C}_{3}$, which is implied by $w>0.5 \alpha C_{2}$. Thus, Firm 3 acquires Firm 5 if and only if $w>0.5 \alpha C_{2}$. It can be easily seen that Firm 3 acquires Firm 4 under the same condition and that the payoff of Firm 3's manager in this case is the same as if he acquired Firm 5 , namely, $w-0.5\left(w-0.5 \alpha C_{3}\right)$. By assumption, he resolves this indifference in favor of acquiring the smaller firm, Firm 5. Hence, we can summarize Firm 3's behavior as follows:

Firm 3 acquires Firm 5 in the good state at date 1 if and only if $\mathrm{w}>0.5 \alpha \mathrm{C}_{2}$.

Firm 4 moves before Firm 3. If it acquires Firm 5, its manager gets up to $w$. If he does not acquire Firm 5, two situations can arise. If $\mathrm{w} \leq 0.5 \alpha \mathrm{C}_{2}$, Firms 3 and 2 will be passive and Firm 1 will acquire Firm 2. Hence, Firm 4's manager receives $w$ and thus does not acquire Firm 5. However, if $\mathrm{w}>0.5 \alpha \mathrm{C}_{2}$, Firm 3 will acquire Firm 5. Afterwards, Firm 2 will acquire Firm 4, because then its manager gets up to $w$ while otherwise Firm 2 would be acquired by Firm 1 and Firm 2's manager would receive only $0.5 \alpha \mathrm{C}_{2}$. Firm 4's manager receives a payoff of $0.5\left(w-0.5 \alpha C_{2}\right)$ if Firm 4 is acquired by Firm 2. Hence, Firm 4 acquires Firm 5 if and only if 
$\mathrm{w}>0.5\left(\mathrm{w}-0.5 \alpha \mathrm{C}_{2}\right)$, which is always satisfied. Hence, we can summarize Firm 4's behavior as follows:

Firm 4 acquires Firm 5 in the good state at date 1 if and only if $\mathrm{w}>0.5 \alpha \mathrm{C}_{2}$.

From the firms' strategies highlighted in italics, keeping in mind that Firm 4 moves first, Firm 3 second, Firm 2 third, and Firm 1 fourth, one can easily see that the equilibrium outcome under the different parameter constellations is as described in Lemma 1. If (3) holds, Firm 4 acquires Firm 5. Will then Firm 2 acquire Firm 3? If Firm 2 acquires Firm 3, its manager receives a payoff of up to $w$. If Firm 2 does not acquire Firm 3, it is acquired by Firm 1 and its manager receives a payoff of $0.5 \alpha C_{2}$. Hence, Firm 2 acquires Firm 3 after Firm 4 acquires Firm 5.

The precise statement of Proposition 2 is:

Proposition 2: If (3) does not hold, i.e., $\mathrm{w} \leq 0.5 \alpha \mathrm{C}_{2}$, Firm 1 acquires Firm 2 in the good state at date 1 . This acquisition is profitable. If $\mathrm{w} \in\left(0.5 \alpha \mathrm{C}_{2}, 0.5 \alpha \mathrm{C}_{2}+2 \alpha \frac{1-\rho}{\rho} \mathrm{C}_{3}\right]$, Firm 4 acquires Firm 5 at date 0 and then Firm 2 acquires Firm 3 in the good state at date 1 unless $0.5 \alpha \mathrm{C}_{2}<2 \alpha \frac{1-\rho}{\rho} \mathrm{C}_{5}-0.5 \alpha \mathrm{C}_{2}$ and $\mathrm{w} \in\left(0.5 \alpha \mathrm{C}_{2}, 2 \alpha \frac{1-\rho}{\rho} \mathrm{C}_{5}-0.5 \alpha \mathrm{C}_{2}\right]$. In this case, Firm 4 acquires Firm 5 in the good state at date 1. Then Firm 2 acquires Firm 3 in the good state at date 1. Finally, if $\mathrm{w}>0.5 \alpha \mathrm{C}_{2}+2 \alpha \frac{1-\rho}{\rho} \mathrm{C}_{3}$, Firm 4 acquires Firm 5 at date 0 . Then Firm 2 acquires Firm 3 at date 0 . All of these acquisitions are unprofitable.

Proof of Proposition 2: Lemma 1 has shown which mergers occur at date 1. Now we turn to date 0 . Firm 1 is the last firm to move at this date. If Firm 1 acquires Firm $j$, Firm 1 's manager gets up to $2 \mathrm{w}+\alpha\left(\rho \mathrm{C}_{\mathrm{j}}-(1-\rho) \mathrm{C}_{\mathrm{j}}\right)$. Because it was assumed that $\rho<0.5$ (assumption (1)), this is less than the payoff that Firm 1's manager receives if he does not acquire Firm $j$, which is at least $2 w$. Note also that there is no incentive for Firm 1 to acquire any other firm in order to improve its acquisition opportunities at date 1 since it can make only one acquisition. Hence, we can summarize Firm 1's behavior as follows:

Firm 1 does not acquire any other firm at date 0.

Firm 2 moves before Firm 1. If Firm 2 acquires Firm 5, its manager receives up to $2 \mathrm{w}-\alpha(1-\rho) \mathrm{C}_{5}$. If Firm 2 does not acquire Firm 5, several situations can arise, as shown in 
Lemma 1. If $\mathrm{w} \leq 0.5 \alpha \mathrm{C}_{2}$, Firm 1 acquires Firm 2 in the good state at date 1 and Firm 2's manager receives $\mathrm{w}+(1-\rho) \mathrm{w}+\rho 0.5 \alpha \mathrm{C}_{2}$. Hence, it can be easily calculated that Firm 2 acquires Firm 5 if and only if $w>0.5 \alpha C_{2}+\alpha \frac{1-\rho}{\rho} C_{5}$, which is inconsistent with $w \leq 0.5 \alpha C_{2}$. Thus, Firm 2 does not acquire Firm 5 if $\mathrm{w} \leq 0.5 \alpha \mathrm{C}_{2}$. Now assume that $w>0.5 \alpha C_{2}$. If Firm 2 does not acquire Firm 5, Firm 4 acquires Firm 5 in the good state at date 1, as was shown in Lemma 1. Will then Firm 2 acquire Firm 3 in the good state at date 1? If Firm 2 acquires Firm 3, its manager receives a payoff of up to $w$. If Firm 2 does not acquire Firm 3, Firm 2 is acquired by Firm 1 and its manager receives $0.5 \alpha C_{2}$. Hence, Firm 2 acquires Firm 3 if and only if $w>0.5 \alpha C_{2}$, which we have assumed. Thus, Firm 2 acquires Firm 3 in the good state at date 1 . It will pay a price of $\mathrm{C}_{3}+0.5 \frac{1}{\alpha}\left(\mathrm{w}-0.5 \alpha \mathrm{C}_{2}\right)$. Hence, Firm 2's manager receives an expected payoff at date 0 of $2 w-\rho 0.5\left(w-0.5 \alpha C_{2}\right)$. Thus, Firm 2 acquires Firm 5 at date 0 if and only if $2 \mathrm{w}-\alpha(1-\rho) \mathrm{C}_{5}>2 \mathrm{w}-\rho 0.5\left(\mathrm{w}-0.5 \alpha \mathrm{C}_{2}\right)$ or $\mathrm{w}>0.5 \alpha \mathrm{C}_{2}+2 \alpha \frac{1-\rho}{\rho} \mathrm{C}_{5}$.

It can be shown in a similar way that Firm 2 wants to acquire Firm 4 if and only if $\mathrm{w}>0.5 \alpha \mathrm{C}_{2}+2 \alpha \frac{1-\rho}{\rho} \mathrm{C}_{4}$ and that Firm 2 wants to acquire Firm 3 if and only if $\mathrm{w}>0.5 \alpha \mathrm{C}_{2}+2 \alpha \frac{1-\rho}{\rho} \mathrm{C}_{3}$. It can also be shown that Firm 2's manager always prefers to acquire Firm 5 to acquiring Firm 4 or Firm 3. Hence, we can summarize Firm 2's behavior as follows:

Firm 2 acquires Firm 5 at date 0 if and only if $\mathrm{w}>0.5 \alpha \mathrm{C}_{2}+2 \alpha \frac{1-\rho}{\rho} \mathrm{C}_{5}$.

Firm 3 moves before Firm 2. If Firm 3 acquires Firm 5, its manager receives up to $2 \mathrm{w}-\alpha(1-\rho) \mathrm{C}_{5}$. If Firm 3 does not acquire Firm 5, several situations can arise, as shown above and in Lemma 1. If $\mathrm{w} \leq 0.5 \alpha \mathrm{C}_{2}$, Firm 1 acquires Firm 2 in the good state at date 1 and Firm 3 remains independent. Then Firm 3's manager receives $2 w$, which is strictly larger than $2 \mathrm{w}-\alpha(1-\rho) \mathrm{C}_{5}$. As a consequence, Firm 3 does not acquire Firm 5. If $\mathrm{w} \in\left(0.5 \alpha \mathrm{C}_{2}, 0.5 \alpha \mathrm{C}_{2}+2 \alpha \frac{1-\rho}{\rho} \mathrm{C}_{5}\right]$, Firm 2 will not acquire Firm 5 at date 0. However, Firm 4, the first to move at date 1, will acquire Firm 5 in the good state at date 1, as seen from Lemma 1. Will then Firm 2 acquire Firm 3 in the good state at date 1? If it does so, its manager receives up to $w$ and if not it is acquired by Firm 1 and its manager receives $0.5 \alpha C_{2}$. Since $w>0.5 \alpha C_{2}$, 
Firm 2 acquires Firm 3 for $C_{3}+0.5 \frac{1}{\alpha}\left(\mathrm{w}-0.5 \alpha \mathrm{C}_{2}\right)$ and the expected payoff of Firm 3's manager at date 0 is $w+(1-\rho) w+\rho 0.5\left(w-0.5 \alpha C_{2}\right)$. Hence, Firm 3 acquires Firm 5 if and only if $2 w-\alpha(1-\rho) C_{5}>w+(1-\rho) w+\rho 0.5\left(w-0.5 \alpha C_{2}\right)$ or $w>2 \alpha \frac{1-\rho}{\rho} C_{5}-0.5 \alpha C_{2}$. Thus, Firm 3 acquires Firm 5 if and only if $\mathrm{w}>\max \left\{0.5 \alpha \mathrm{C}_{2}, 2 \alpha \frac{1-\rho}{\rho} \mathrm{C}_{5}-0.5 \alpha \mathrm{C}_{2}\right\}$.

Finally, consider the parameter region $\mathrm{w}>0.5 \alpha \mathrm{C}_{2}+2 \alpha \frac{1-\rho}{\rho} \mathrm{C}_{5}$. If Firm 3 does not acquire Firm 5, Firm 2 acquires Firm 5 at date 0, as shown above. Will then Firm 3 acquire Firm 4 in the good state at date 1? If it does so, Firm 3's manager receives up to $w$. If Firm 3 does not acquire Firm 4, Firm 3 is the largest remaining firm in the good state at date 1 that Firm 1 can acquire and hence is acquired by Firm 1 at a price of $C_{3}+0.5 C_{3}$. In this case, Firm 3's manager receives $0.5 \alpha C_{3}$. But this is smaller than $w$ since we assumed $w>0.5 \alpha C_{2}+2 \alpha \frac{1-\rho}{\rho} C_{5}$. Hence, Firm 3 acquires Firm 4 in the good state at date 1 for $\mathrm{C}_{4}+0.5 \frac{1}{\alpha}\left(\mathrm{w}-0.5 \alpha \mathrm{C}_{3}\right)$ and Firm 3's manager receives an expected payoff at date 0 of $2 \mathrm{w}-\rho 0.5\left(\mathrm{w}-0.5 \alpha \mathrm{C}_{3}\right)$ if he does not acquire Firm 5 at date 0 . As a consequence, Firm 3 acquires Firm 5 at date 0 if and only if $2 \mathrm{w}-\alpha(1-\rho) \mathrm{C}_{5}>2 \mathrm{w}-\rho 0.5\left(\mathrm{w}-0.5 \alpha \mathrm{C}_{3}\right)$ or $\mathrm{w}>0.5 \alpha \mathrm{C}_{3}+2 \alpha \frac{1-\rho}{\rho} \mathrm{C}_{5}$. But this is always satisfied since we have assumed $\quad \mathrm{w}>0.5 \alpha \mathrm{C}_{2}+2 \alpha \frac{1-\rho}{\rho} \mathrm{C}_{5}$. Since $0.5 \alpha C_{2}+2 \alpha \frac{1-\rho}{\rho} C_{5}>2 \alpha \frac{1-\rho}{\rho} C_{5}-0.5 \alpha C_{2}$, we can say that Firm 3 acquires Firm 5 if and only if $\mathrm{w}>\max \left\{0.5 \alpha \mathrm{C}_{2}, 2 \alpha \frac{1-\rho}{\rho} \mathrm{C}_{5}-0.5 \alpha \mathrm{C}_{2}\right\}$.

It can be calculated in a similar way under which conditions Firm 3 wants to acquire Firm 4 at date 0 and that whenever that is the case, Firm 3 prefers to acquire Firm 5 to acquiring Firm 4. As a consequence, we can summarize Firm 3's behavior as follows.

Firm 3 acquires Firm 5 at date 0 if and only if $\mathrm{w}>\max \left\{0.5 \alpha \mathrm{C}_{2}, 2 \alpha \frac{1-\rho}{\rho} \mathrm{C}_{5}-0.5 \alpha \mathrm{C}_{2}\right\}$.

Finally, let us turn to Firm 4, which moves first and before Firm 3. First let us assume that 
$0.5 \alpha C_{2}<2 \alpha \frac{1-\rho}{\rho} C_{5}-0.5 \alpha C_{2}$. If Firm 4 acquires Firm 5, Firm 4's manager receives a payoff of up to $2 \mathrm{w}-\alpha(1-\rho) \mathrm{C}_{5}$. If Firm 4 does not acquire Firm 5, several situations can arise, as shown above. If $\mathrm{w} \leq 0.5 \alpha \mathrm{C}_{2}$, Firm 1 acquires Firm 2 in the good state at date 1 and hence Firm 4's manager receives $2 w$, which is larger than $2 w-\alpha(1-\rho) C_{5}$. Hence, Firm 4 does not acquire Firm 5.

Next consider the parameter region $\mathrm{w} \in\left(0.5 \alpha \mathrm{C}_{2}, 2 \alpha \frac{1-\rho}{\rho} \mathrm{C}_{5}-0.5 \alpha \mathrm{C}_{2}\right]$. If Firm 4 does not acquire Firm 5 at date 0 , there is no acquisition at date 0 . As shown above, in this parameter region Firm 3 does not acquire Firm 5 or any other firm at date 0. Moreover, Firm 2 does not acquire Firm 5 or any other firm at date 0 , because $2 \alpha \frac{1-\rho}{\rho} C_{5}-0.5 \alpha C_{2}<0.5 \alpha C_{2}+2 \alpha \frac{1-\rho}{\rho} C_{5}$.

The first firm to move at date 1, Firm 4, will acquire Firm 5 in the good state at date 1, as seen in Lemma 1. To calculate the payoff of Firm 4's manager in this case, we need to calculate the price he pays for acquiring Firm 5 at date 1. This depends on his payoff if he acquires Firm 5 at a zero premium and his payoff if he does not acquire Firm 5. If Firm 4 acquires Firm 5 at date 1, Firm 4's manager receives up to $w$. If Firm 4 does not acquire Firm 5, Firm 3 gets to move and acquires Firm 5, as seen in Lemma 1. Will then Firm 2 acquire Firm 4 at date 1? If Firm 2 acquires Firm 4 at date 1, its manager receives up to $w$. If Firm 2 does not acquire Firm 4, then it is acquired by Firm 1 and Firm 2's manager receives a payoff of $0.5 \alpha C_{2}$. Hence, Firm 2 acquires Firm 4 if and only if $\mathrm{w}>0.5 \alpha \mathrm{C}_{2}$, which was assumed to hold. Firm 2 will pay $\mathrm{C}_{4}+0.5 \frac{1}{\alpha}\left(\mathrm{w}-0.5 \alpha \mathrm{C}_{2}\right) \quad$ for Firm 4. Hence, Firm 4's manager pays $\mathrm{C}_{5}+0.5 \frac{1}{\alpha}\left(\mathrm{w}-0.5\left(\mathrm{w}-0.5 \alpha \mathrm{C}_{2}\right)\right)$, for Firm 5 in the good state at date 1 . As a consequence, Firm 4's manager receives an expected payoff of $2 \mathrm{w}-\rho 0.5\left(\mathrm{w}-0.5\left(\mathrm{w}-0.5 \alpha \mathrm{C}_{2}\right)\right)$ at date 0 if he does not acquire Firm 4 at date 0 (but in the good state at date 1). Thus, Firm 4 acquires Firm 5 at date 0 if and only if $2 w-\alpha(1-\rho) C_{5}>2 w-\rho 0.5\left(w-0.5\left(w-0.5 \alpha C_{2}\right)\right)$ or $w>4 \alpha \frac{1-\rho}{\rho} C_{5}-0.5 \alpha C_{2}$. Since $4 \alpha \frac{1-\rho}{\rho} C_{5}-0.5 \alpha C_{2}>2 \alpha \frac{1-\rho}{\rho} C_{5}-0.5 \alpha C_{2}$ (recall that the right hand side is the upper 
bound of the parameter region we are considering currently), we can conclude that Firm 4 never acquires Firm 5 in the parameter region $w \in\left(0.5 \alpha C_{2}, 2 \alpha \frac{1-\rho}{\rho} C_{5}-0.5 \alpha C_{2}\right]$.

Finally, we consider the parameter region $\mathrm{w}>2 \alpha \frac{1-\rho}{\rho} \mathrm{C}_{5}-0.5 \alpha \mathrm{C}_{2}$. If Firm 4 does not acquire Firm 5, Firm 3 acquires Firm 5 at date 0 as shown above. Will then Firm 2 acquire Firm 4 at date 0? If Firm 2 acquires Firm 4 at date 0, Firm 2's manager receives a payoff of up to $2 \mathrm{w}-\alpha(1-\rho) \mathrm{C}_{4}$. If Firm 2 does not acquire Firm 4 at date 0 , will it acquire Firm 4 in the good state at date 1? If Firm 2 acquires Firm 4 in the good state at date 1, its manager receives up to w. If Firm 2 does not acquire Firm 4, it is acquired by Firm 1 and Firm 2's manager receives a payoff of $0.5 \alpha \mathrm{C}_{2}$. Hence, Firm 2 acquires Firm 4 in the good state at date 1 if and only if $\mathrm{w}>0.5 \alpha \mathrm{C}_{2}$, which was assumed to hold. It will pay a price of $\mathrm{C}_{4}+0.5 \frac{1}{\alpha}\left(\mathrm{w}-0.5 \alpha \mathrm{C}_{2}\right)$. Hence, Firm 2's manager receives an expected payoff at date 0 of $2 w-\rho 0.5\left(w-0.5 \alpha C_{2}\right)$. Thus, Firm 2 acquires Firm 4 at date 0 if and only if $2 w-\alpha(1-\rho) C_{4}>2 w-\rho 0.5\left(w-0.5 \alpha C_{2}\right)$ or $\mathrm{w}>0.5 \alpha \mathrm{C}_{2}+2 \alpha \frac{1-\rho}{\rho} \mathrm{C}_{4}$. Otherwise, Firm 2 acquires Firm 4 in the good state at date 1 . We can use this information to calculate the payoff of Firm 4's manager if he does not acquire Firm 5 at date 0 . If $\mathrm{w} \leq 0.5 \alpha \mathrm{C}_{2}+2 \alpha \frac{1-\rho}{\rho} \mathrm{C}_{4}$, Firm 2 acquires Firm 4 in the good state at date 1 if Firm 4 does not acquire Firm 5 at date 0 . In this case, Firm 4's manager receives an expected payoff at date 0 of $w+(1-\rho) w+\rho 0.5\left(w-0.5 \alpha C_{2}\right)$. Hence, Firm 4 acquires Firm 5 at date 0 if and only if $2 \mathrm{w}-\alpha(1-\rho) \mathrm{C}_{5}>\mathrm{w}+(1-\rho) \mathrm{w}+\rho 0.5\left(\mathrm{w}-0.5 \alpha \mathrm{C}_{2}\right)$ or $\mathrm{w}>2 \alpha \frac{1-\rho}{\rho} \mathrm{C}_{5}-0.5 \alpha \mathrm{C}_{2}$. But this is always satisfied, because we have assumed that $\mathrm{w}>2 \alpha \frac{1-\rho}{\rho} \mathrm{C}_{5}-0.5 \alpha \mathrm{C}_{2}$.

If $\mathrm{w}>0.5 \alpha \mathrm{C}_{2}+2 \alpha \frac{1-\rho}{\rho} \mathrm{C}_{4}$, Firm 2 acquires Firm 4 at date 0 if Firm 4 does not acquire Firm 5 at date 0 Firm 2 will pay a price of $\mathrm{C}_{4}+0.5 \frac{1}{\alpha}\left(2 \mathrm{w}-\alpha(1-\rho) \mathrm{C}_{4}-2 \mathrm{w}+\rho 0.5\left(\mathrm{w}-0.5 \alpha \mathrm{C}_{2}\right)\right)$ for Firm 4 , because this price enables Firm 2's manager to keep one half of his utility gain from acquiring Firm 4 at date 0 at a zero premium instead of in the good state at date 1. Hence, Firm 4's manager receives a payoff of 
$0.5\left(2 \mathrm{w}-\alpha(1-\rho) \mathrm{C}_{4}-2 \mathrm{w}+\rho 0.5\left(\mathrm{w}-0.5 \alpha \mathrm{C}_{2}\right)\right)$. As a consequence, Firm 4 acquires Firm 5 at date 0 if and only if $2 \mathrm{w}-\alpha(1-\rho) \mathrm{C}_{5}>0.5\left(2 \mathrm{w}-\alpha(1-\rho) \mathrm{C}_{4}-2 \mathrm{w}+\rho 0.5\left(\mathrm{w}-0.5 \alpha \mathrm{C}_{2}\right)\right)$ or $\mathrm{w}>\frac{\alpha(1-\rho) \mathrm{C}_{5}}{2-0.25 \rho}-\frac{0.5 \alpha(1-\rho) \mathrm{C}_{4}}{2-0.25 \rho}-\frac{0.125 \alpha \rho \mathrm{C}_{2}}{2-0.25 \rho}$. But this is always satisfied if $\mathrm{w}>0.5 \alpha \mathrm{C}_{2}+2 \alpha \frac{1-\rho}{\rho} \mathrm{C}_{4}$.

As a consequence of the discussion above, we can conclude that Firm 4 acquires Firm 5 whenever $w>2 \alpha \frac{1-\rho}{\rho} C_{5}-0.5 \alpha C_{2}$. From the discussion above we can summarize Firm 4 's behavior at date 0 if $0.5 \alpha C_{2}<2 \alpha \frac{1-\rho}{\rho} C_{5}-0.5 \alpha C_{2}$ as follows.

Firm 4 acquires Firm 5 at date 0 if and only if $\mathrm{w}>2 \alpha \frac{1-\rho}{\rho} \mathrm{C}_{5}-0.5 \alpha \mathrm{C}_{2}$.

Finally, let us consider Firm 4's behavior at date 0 if $0.5 \alpha C_{2} \geq 2 \alpha \frac{1-\rho}{\rho} C_{5}-0.5 \alpha C_{2}$. Then, Firm 3 acquires Firm 5 at date 0 if and only if $w>0.5 \alpha C_{2}$, as shown above. If Firm 4 acquires Firm 5 at date 0 , its manager receives up to $2 w-\alpha(1-\rho) C_{5}$. If Firm 4 does not acquire Firm 5 at date 0 , several situations can arise, as shown above and in Lemma 1.

If $\mathrm{w} \leq 0.5 \alpha \mathrm{C}_{2}$, the only acquisition is Firm 1 acquiring Firm 2 in the good state at date 1. Firm 4 remains independent and its manager receives $2 w$. But this is larger than $2 \mathrm{w}-\alpha(1-\rho) \mathrm{C}_{5}$, and hence Firm 4 does not acquire Firm 5 at date 0.

Now consider the parameter region in which $\mathrm{w}>0.5 \alpha \mathrm{C}_{2}$. If Firm 4 does not acquire Firm 5 at date 0, Firm 3 acquires Firm 5 at date 0, as shown above. Will then Firm 2 acquire Firm 4 at date 0? If Firm 2 acquires Firm 4 at date 0, Firm 2's manager receives a payoff of up to $2 \mathrm{w}-\alpha(1-\rho) \mathrm{C}_{4}$. If Firm 2 does not acquire Firm 4 at date 0 , it may still acquire it in the good state at date 1. Will Firm 2 do so? If Firm 2 acquires Firm 4 in the good state at date 1, Firm 2's manager receives a payoff of up to $w$. If Firm 2 does not acquire Firm 4, it is acquired by Firm 1 and Firm 2's manager receives a payoff of $0.5 \alpha \mathrm{C}_{2}$. Hence, Firm 2 acquires Firm 4 in the good state at date 1 if and only if $\mathrm{w}>0.5 \alpha \mathrm{C}_{2}$, which we assumed to hold. Firm 2 will pay a price of $\mathrm{C}_{4}+0.5 \frac{1}{\alpha}\left(\mathrm{w}-0.5 \alpha \mathrm{C}_{2}\right)$ for Firm 4. Hence, Firm 2's manager receives an expected payoff at date 0 of $2 w-\rho 0.5\left(w-0.5 \alpha C_{2}\right)$ if he does not acquire Firm 4 at date 0 . As a consequence, Firm 
2 acquires Firm 4 at date 0 if and only if $2 w-\alpha(1-\rho) C_{4}>2 w-\rho 0.5\left(w-0.5 \alpha C_{2}\right)$ or $\mathrm{w}>0.5 \alpha \mathrm{C}_{2}+2 \alpha \frac{1-\rho}{\rho} \mathrm{C}_{4}$. Otherwise, Firm 2 acquires Firm 4 in the good state at date 1 . We can use this information to calculate the payoff of Firm 4's manager if he does not acquire Firm 5 at date 0 .

If $\mathrm{w} \leq 0.5 \alpha \mathrm{C}_{2}+2 \alpha \frac{1-\rho}{\rho} \mathrm{C}_{4}$, Firm 2 acquires Firm 4 in the good state at date 1. Hence, Firm 4's manager receives an expected payoff at date 0 of $w+(1-\rho) w+\rho 0.5\left(w-0.5 \alpha C_{2}\right)$. This implies that Firm 4 acquires Firm 5 at date 0 if and only if $2 \mathrm{w}-\alpha(1-\rho) \mathrm{C}_{5}>\mathrm{w}+(1-\rho) \mathrm{w}+\rho 0.5\left(\mathrm{w}-0.5 \alpha \mathrm{C}_{2}\right)$ or $\mathrm{w}>2 \alpha \frac{1-\rho}{\rho} \mathrm{C}_{5}-0.5 \alpha \mathrm{C}_{2}$. But this is always true if $\mathrm{w}>0.5 \alpha \mathrm{C}_{2}$, since we are considering the parameter region in which $0.5 \alpha \mathrm{C}_{2} \geq 2 \alpha \frac{1-\rho}{\rho} \mathrm{C}_{5}-0.5 \alpha \mathrm{C}_{2}$.

Finally, if $w>0.5 \alpha C_{2}+2 \alpha \frac{1-\rho}{\rho} C_{4}$, Firm 2 acquires Firm 4 at date 0 after Firm 3 acquires Firm 5 at date 0 . Firm 4's manager receives a payoff of $0.5\left(2 \mathrm{w}-\alpha(1-\rho) \mathrm{C}_{4}-2 \mathrm{w}+\rho 0.5\left(\mathrm{w}-0.5 \alpha \mathrm{C}_{2}\right)\right)$. This is derived using the price that Firm 2 pays for Firm 4 at date 0, which ensures that Firm 2's manager keeps one half of the difference between his utility if he acquires Firm 4 at date 0 at a zero premium and if he acquires Firm 4 at date 1. Hence, Firm 4 acquires Firm 5 at date 0 if and only if $2 \mathrm{w}-\alpha(1-\rho) \mathrm{C}_{5}>0.5\left(2 \mathrm{w}-\alpha(1-\rho) \mathrm{C}_{4}-2 \mathrm{w}+\rho 0.5\left(\mathrm{w}-0.5 \alpha \mathrm{C}_{2}\right)\right) \quad$ or $\mathrm{w}>\frac{\alpha(1-\rho) \mathrm{C}_{5}}{2-0.25 \rho}-\frac{0.5 \alpha(1-\rho) \mathrm{C}_{4}}{2-0.25 \rho}-\frac{0.125 \alpha \rho \mathrm{C}_{2}}{2-0.25 \rho}$. But this is always satisfied, since we are considering the parameter region in which $\mathrm{w}>0.5 \alpha \mathrm{C}_{2}+2 \alpha \frac{1-\rho}{\rho} \mathrm{C}_{4}$. Overall, we can conclude that Firm 4 acquires Firm 5 at date 0 whenever $\mathrm{w}>0.5 \alpha \mathrm{C}_{2}$ holds.

We can summarize Firm 4's behavior at date 0 if $0.5 \alpha C_{2} \geq 2 \alpha \frac{1-\rho}{\rho} C_{5}-0.5 \alpha C_{2}$ holds as follows.

Firm 4 acquires Firm 5 at date 0 if and only if $\mathrm{w}>0.5 \alpha \mathrm{C}_{2}$.

To complete the proof of Proposition 2, we have to calculate the equilibrium merger activity arising from the firms' behavior summarized in the statements in italics. It is easy to verify (keep- 
ing in mind that Firm 4 moves first, Firm 3 second, Firm 2 third, and Firm 1 last at each date) that the merger activity as described in Proposition 2 is the only equilibrium merger activity.

Suppose that $0.5 \alpha C_{2} \geq 2 \alpha \frac{1-\rho}{\rho} C_{5}-0.5 \alpha C_{2}$. If $\mathrm{w} \leq 0.5 \alpha \mathrm{C}_{2}$, Firm 1 acquires Firm 2 in the good state at date 1 . Clearly, this acquisition is profitable. Since Firm 1 is the last firm to move, there cannot be another acquisition afterwards. If $w>0.5 \alpha C_{2}$, Firm 4 acquires Firm 5 at date 0 . Will then Firm 2 acquire Firm 3 at date 0? If Firm 2 acquires Firm 3 at date 0, its manager receives up to $2 w-\alpha(1-\rho) C_{3}$. If Firm 2 does not acquire Firm 3 at date 0, Firm 1 will not make an acquisition at date 0 (it would be unprofitable and it can make only one acquisition in total). Will then Firm 2 acquire Firm 3 in the good state at date 1? If Firm 2 acquires Firm 3 in the good state at date 1, Firm 2's manager receives up to $w$. If Firm 2 does not acquire Firm 3, it is acquired by Firm 1 and its manager receives $0.5 \alpha C_{2}$. Hence, Firm 2 acquires Firm 3 in the good state at date 1 if it does not do so at date 0 . It pays $C_{3}+0.5 \frac{1}{\alpha}\left(w-0.5 \alpha C_{2}\right)$. Hence, Firm 2's manager receives an expected payoff at date 0 of $2 w-0.5 \rho\left(w-0.5 \alpha C_{2}\right)$ if it does not acquire Firm 3 at date 0 (but in the good state at date 1). Thus, Firm 2 acquires Firm 3 at date 0 if and only if $2 w-\alpha(1-\rho) C_{3}>2 w-0.5 \rho\left(w-0.5 \alpha C_{2}\right)$ or $w>2 \alpha \frac{1-\rho}{\rho} C_{3}+0.5 \alpha C_{2}$. Hence, after Firm 4 acquires Firm 5 at date 0 , Firm 2 acquires Firm 3 at date 1 if $w \in\left(0.5 \alpha C_{2}, 0.5 \alpha C_{2}+2 \alpha \frac{1-\rho}{\rho} C_{3}\right]$. Firm 2 acquires Firm 3 at date 0 if $w>0.5 \alpha C_{2}+2 \alpha \frac{1-\rho}{\rho} C_{3}$. Both the date 0 acquisition of Firm 5 by Firm 4 and the date 0 acquisition of Firm 3 by Firm 2 are unprofitable, because they create negative synergies but involve a positive premium. The acquisition of Firm 3 by Firm 2 in the good state at date 1 is also unprofitable, because it creates zero synergies but involves a positive premium.

Suppose now that $0.5 \alpha C_{2}<2 \alpha \frac{1-\rho}{\rho} C_{5}-0.5 \alpha C_{2}$. If $\mathrm{w} \leq 0.5 \alpha \mathrm{C}_{2}$, Firm 1 acquires Firm 2 in the good state at date 1 . Clearly, this acquisition is profitable. Since Firm 1 is the last firm to move, there cannot be another acquisition afterwards. If $w \in\left(0.5 \alpha C_{2}, 2 \alpha \frac{1-\rho}{\rho} C_{5}-0.5 \alpha C_{2}\right]$, Firm 4 acquires Firm 5 in the good state at date 1. Will then Firm 2 acquire Firm 3 at date 1? If Firm 2 acquires Firm 3, its manager receives a payoff of $w$. If Firm 2 does not acquire Firm 3, it will be acquired by Firm 1 and its manager receives a payoff of $0.5 \alpha C_{2}$. Hence, Firm 2 acquires Firm 3 
in the good state at date 1 after Firm 4 acquires Firm 5. If $w>2 \alpha \frac{1-\rho}{\rho} C_{5}-0.5 \alpha C_{2}$, Firm 4 acquires Firm 5 at date 0 . Will then Firm 2 acquire Firm 3 at date 0 ? Here the calculations are the same as in the case $0.5 \alpha C_{2} \geq 2 \alpha \frac{1-\rho}{\rho} C_{5}-0.5 \alpha C_{2}$ above: Firm 2 acquires Firm 3 at date 0 if and only if $2 w-\alpha(1-\rho) C_{3}>2 w-0.5 \rho\left(w-0.5 \alpha C_{2}\right)$ or $w>2 \alpha \frac{1-\rho}{\rho} C_{3}+0.5 \alpha C_{2}$. Hence, after Firm 4 acquires Firm 5 at date 0, Firm 2 acquires Firm 3 in the good state at date 1 if $w \in\left(2 \alpha \frac{1-\rho}{\rho} C_{5}-0.5 \alpha C_{2}, 0.5 \alpha C_{2}+2 \alpha \frac{1-\rho}{\rho} C_{3}\right]$. Firm 2 acquires Firm 3 at date 0 if $w>0.5 \alpha C_{2}+2 \alpha \frac{1-\rho}{\rho} C_{3}$. As in the case $0.5 \alpha C_{2} \geq 2 \alpha \frac{1-\rho}{\rho} C_{5}-0.5 \alpha C_{2}$, the acquisition of Firm 5 by Firm 4 and the acquisition of Firm 3 by Firm 2 are unprofitable, both at date 0 and in the good state at date 1.

The precise statement of Proposition 3 is:

Proposition 3: If (6) holds, Firm 2 acquires Firm 4 at date 0. Then Firm 1 acquires the combination of Firm 2 and Firm 4 in the good state at date 1. If (6) does not hold, Firm 1 acquires Firm 2 in the good state at date 1 . All acquisitions are profitable.

Proof of Proposition 3: We solve the model by backwards induction. There are no acquisitions in the bad state at date 1 . Firm 1 does not acquire any other firm, because this would be unprofitable. If Firm 1 acquired Firm $j$, it would have to pay at least $C_{j}$. However, Firm $j$ would be worth only zero to Firm 1, due to the negative synergies. Firm 2 and Firm 3 do not have any motives to make acquisitions to change their attractiveness as targets to Firm 1, because Firm 1 has already moved and will not move again. They will not make any acquisitions in the bad state at date 1 , since they would be unprofitable, as was already shown for Firm 1. We can summarize the behavior of firms in the bad state at date 1 as follows.

There are no acquisitions in the bad state at date 1.

Now we turn to the good state at date 1 . Firm 1 acquires the largest remaining firm. If no acquisition has occurred yet, it acquires Firm 2. No other firm has an incentive to make an acquisition afterwards. If Firm 3 acquires Firm 4, it has to pay at least $C_{4}$. But Firm 4 is worth exactly 
the same amount $C_{4}$ if combined with Firm 3. Hence, Firm 3 cannot make a profit by acquiring Firm 4. It also has no incentive to make an acquisition to change its attractiveness as a target to Firm 1, because Firm 1 has already moved and will not move again. We can summarize the behavior of the firms in the good state at date 1 as follows.

Firm 1 acquires Firm 2 in the good state at date 1. There is no other acquisition in the good state at date 1.

Now we turn to date 0. The last firm to move at this date is Firm 3. If Firm 3 acquires Firm 4, it becomes the largest firm other than Firm 1 and hence will be acquired by Firm 1 in the good state at date 1 at a price $C_{3}+C_{4}+0.5\left(C_{3}+C_{4}\right)$. Hence, Firm 3's manager receives an expected payoff at date 0 of up to $w+(1-\rho)\left(w-\alpha C_{4}\right)+\rho \alpha 0.5\left(C_{3}+C_{4}\right)$ if he acquires Firm 4 at date 0 . If Firm 3 does not acquire Firm 4 at date 0, Firm 2 remains the second largest firm and is acquired by Firm 1 in the good state at date 1 . Hence, Firm 3 remains independent and its manager receives a payoff of $2 w$. As a consequence, Firm 3 acquires Firm 4 at date 0 if and only if $\mathrm{w}+(1-\rho)\left(\mathrm{w}-\alpha \mathrm{C}_{4}\right)+\rho \alpha 0.5\left(\mathrm{C}_{3}+\mathrm{C}_{4}\right)>2 \mathrm{w}$ or $\mathrm{w}<0.5 \alpha\left(\mathrm{C}_{3}+\mathrm{C}_{4}\right)-\alpha \frac{1-\rho}{\rho} \mathrm{C}_{4}$. We can summarize Firm 3’s behavior at date 0 as follows.

Firm 3 acquires Firm 4 at date 0 if and only if $\mathrm{w}<0.5 \alpha\left(\mathrm{C}_{3}+\mathrm{C}_{4}\right)-\alpha \frac{1-\rho}{\rho} \mathrm{C}_{4}$.

Firm 2 moves before Firm 3 at date 0. If Firm 2 acquires Firm 4 at date 0, it ensures that it will be the second largest firm and hence will be acquired by Firm 1 in the good state at date 1 for a price of $\mathrm{C}_{2}+\mathrm{C}_{4}+0.5\left(\mathrm{C}_{2}+\mathrm{C}_{4}\right)$. Hence, its manager receives an expected payoff at date 0 of up to $\mathrm{w}+(1-\rho)\left(\mathrm{w}-\alpha \mathrm{C}_{4}\right)+\rho \alpha 0.5\left(\mathrm{C}_{2}+\mathrm{C}_{4}\right)$. If Firm 2 does not acquire Firm 4 at date 0 , several situations can arise, as was shown above. If $\mathrm{w}<0.5 \alpha\left(\mathrm{C}_{3}+\mathrm{C}_{4}\right)-\alpha \frac{1-\rho}{\rho} \mathrm{C}_{4}$, Firm 3 acquires Firm 4 at date 0 . In this case, Firm 1 acquires the combination of Firm 3 and Firm 4 in the good state at date 1 and Firm 2 remains independent. Hence, its manager receives a payoff of $2 w$. Thus, Firm 2 acquires Firm 4 at date 0 if and only if $\mathrm{w}+(1-\rho)\left(\mathrm{w}-\alpha \mathrm{C}_{4}\right)+\rho \alpha 0.5\left(\mathrm{C}_{2}+\mathrm{C}_{4}\right)>2 \mathrm{w}$ or $\mathrm{w}<0.5 \alpha\left(\mathrm{C}_{2}+\mathrm{C}_{4}\right)-\alpha \frac{1-\rho}{\rho} \mathrm{C}_{4}$. Since we are considering the parameter region in which $\mathrm{w}<0.5 \alpha\left(\mathrm{C}_{3}+\mathrm{C}_{4}\right)-\alpha \frac{1-\rho}{\rho} \mathrm{C}_{4}$ holds, this implies that Firm 2 acquires Firm 4 whenever $\mathrm{w}<0.5 \alpha\left(\mathrm{C}_{3}+\mathrm{C}_{4}\right)-\alpha \frac{1-\rho}{\rho} \mathrm{C}_{4}$. 
The other situation that can arise if Firm 2 does not acquire Firm 4 is if $\mathrm{w} \geq 0.5 \alpha\left(\mathrm{C}_{3}+\mathrm{C}_{4}\right)-\alpha \frac{1-\rho}{\rho} \mathrm{C}_{4}$ holds. Then Firm 3 does not acquire Firm 4 at date 0 . Firm 2 remains the second largest firm and is acquired by Firm 1 in the good state at date 1 for a price of $\mathrm{C}_{2}+0.5 \mathrm{C}_{2}$. Hence, Firm 2's manager receives an expected payoff at date 0 of $\mathrm{w}+(1-\rho) \mathrm{w}+\rho 0.5 \alpha \mathrm{C}_{2}$. Thus, Firm 2 acquires Firm 4 if and only if $\mathrm{w}+(1-\rho)\left(\mathrm{w}-\alpha \mathrm{C}_{4}\right)+\rho \alpha 0.5\left(\mathrm{C}_{2}+\mathrm{C}_{4}\right)>\mathrm{w}+(1-\rho) \mathrm{w}+\rho \alpha 0.5 \mathrm{C}_{2}$. It can be easily verified that this cannot be true in the parameter region $\mathrm{w} \geq 0.5 \alpha\left(\mathrm{C}_{3}+\mathrm{C}_{4}\right)-\alpha \frac{1-\rho}{\rho} \mathrm{C}_{4}$. Hence, in this parameter region, Firm 2 never acquires Firm 4.

It can also be shown that Firm 2 would want to acquire Firm 3 at date 0 if and only if $\mathrm{w}<\min \left\{0.5 \alpha\left(\mathrm{C}_{3}+\mathrm{C}_{4}\right)-\alpha \frac{1-\rho}{\rho} \mathrm{C}_{4}, 0.5 \alpha\left(\mathrm{C}_{2}+\mathrm{C}_{3}\right)-\alpha \frac{1-\rho}{\rho} \mathrm{C}_{3}\right\}$ and that Firm 2 always prefers to acquire Firm 4 to acquiring Firm 3 at date 0.

We can summarize Firm 2's behavior at date 0 as follows.

Firm 2 acquires Firm 4 at date 0 if and only if $\mathrm{w}<0.5 \alpha\left(\mathrm{C}_{3}+\mathrm{C}_{4}\right)-\alpha \frac{1-\rho}{\rho} \mathrm{C}_{4}$.

Firm 1 moves before Firm 2 at date 0. If Firm 1 acquires Firm $j$, Firm 1's manager receives a payoff of up to $2 \mathrm{w}+\alpha\left(\rho \mathrm{C}_{\mathrm{j}}-(1-\rho) \mathrm{C}_{\mathrm{j}}\right)$. Because it was assumed that $\rho<0.5$ (assumption (1)), this is less than the payoff that Firm 1's manager receives if he does not acquire firm $j$, which is at least $2 w$. Note also that there is no incentive for Firm 1 to acquire any other firm in order to improve its acquisition opportunities at date 1 since it can make only one acquisition. Hence, we can summarize Firm 1's behavior as follows:

Firm 1 does not acquire any other firm at date 0.

To complete the proof of Proposition 3, we have to calculate the equilibrium merger activity arising from the firms' behavior summarized in the statements in italics. It is easy to verify (keeping in mind that Firm 1 moves first, Firm 2 second, Firm 3 third, and Firm 4 last at each date) that the merger activity as described in Proposition 3 is the only equilibrium merger activity. Note that after Firm 2 acquires Firm 4 at date 0, Firm 1 acquires the combination of Firms 2 and 4 in the good state at date 1 . Note also that all acquisitions are profitable.

The precise statement of Proposition 4 is: 
Proposition 4: Suppose that (i) $-4 \alpha \frac{1-\rho}{\rho} C_{5}+\alpha\left(C_{4}+C_{5}\right)+0.5 \alpha C_{3} \leq 0.5 \alpha\left(C_{3}+C_{5}\right)$;

(ii) $0.5 \alpha C_{3}+\alpha\left(C_{4}+C_{5}\right)<0.5 \alpha C_{2}+2 \alpha \frac{1-\rho}{\rho} C_{5}$; and (iii)

$0.5 \alpha C_{2}+2 \alpha \frac{1-\rho}{\rho} C_{5}<0.5 \alpha C_{3}+2 \alpha \frac{1-\rho}{\rho} C_{4}$. Then the following mergers occur in equilibrium: If $\mathrm{w}<-\alpha \frac{1-\rho}{\rho} \mathrm{C}_{5}+0.5 \alpha\left(\mathrm{C}_{4}+\mathrm{C}_{5}\right)$, then Firm 4 acquires Firm 5 at date 0 . Then Firm 1 acquires the combination of Firms 4 and 5 in the good state at date 1. Both acquisitions are profitable. If $\mathrm{w} \in\left[-\alpha \frac{1-\rho}{\rho} \mathrm{C}_{5}+0.5 \alpha\left(\mathrm{C}_{4}+\mathrm{C}_{5}\right),-\alpha \frac{1-\rho}{\rho} \mathrm{C}_{5}+0.5 \alpha\left(\mathrm{C}_{3}+\mathrm{C}_{5}\right)\right)$, then Firm 3 acquires Firm 5 at date 0 . Then Firm 1 acquires the combination of Firms 3 and 5 in the good state at date 1 . Both acquisitions are profitable. If $\mathrm{w} \in\left[-\alpha \frac{1-\rho}{\rho} \mathrm{C}_{5}+0.5 \alpha\left(\mathrm{C}_{3}+\mathrm{C}_{5}\right), 0.5 \alpha\left(\mathrm{C}_{4}+\mathrm{C}_{5}\right)\right)$ and $\mathrm{w} \in\left(0.5 \alpha\left(\mathrm{C}_{3}+\mathrm{C}_{5}\right), 0.5 \alpha \mathrm{C}_{3}+\alpha\left(\mathrm{C}_{4}+\mathrm{C}_{5}\right)\right)$, then Firm 4 acquires Firm 5 in the good state at date 1. Then Firm 1 acquires the combination of Firms 4 and 5 in the good state at date 1 . Both acquisitions are profitable. If $\mathrm{w} \in\left[0.5 \alpha\left(\mathrm{C}_{4}+\mathrm{C}_{5}\right), 0.5 \alpha\left(\mathrm{C}_{3}+\mathrm{C}_{5}\right)\right]$, then Firm 3 acquires Firm 5 in the good state at date 1. Then Firm 1 acquires the combination of Firms 3 and 5 in the good state at date 1. Both acquisitions are profitable. If $\mathrm{w} \in\left[0.5 \alpha \mathrm{C}_{3}+\alpha\left(\mathrm{C}_{4}+\mathrm{C}_{5}\right), 0.5 \alpha \mathrm{C}_{2}+2 \alpha \frac{1-\rho}{\rho} \mathrm{C}_{5}\right]$, then Firm 3 acquires Firm 4 in the good state at date 1. Then Firm 2 acquires Firm 5 in the good state at date 1. Both acquisitions are unprofitable. If $\mathrm{w} \in\left(0.5 \alpha \mathrm{C}_{2}+2 \alpha \frac{1-\rho}{\rho} \mathrm{C}_{5}, 0.5 \alpha \mathrm{C}_{3}+2 \alpha \frac{1-\rho}{\rho} \mathrm{C}_{4}\right]$, then Firm 2 acquires Firm 5 at date 0 . Then Firm 3 acquires Firm 4 in the good state at date 1. Both acquisitions are unprofitable. If $w>0.5 \alpha C_{3}+2 a \frac{1-\rho}{\rho} C_{4}$, Firm 4 acquires Firm 5 at date 0 . This acquisition is unprofitable if $w$ is high enough. Then Firm 1 acquires the combination of Firms 4 and 5 in the good state at date 1 . This acquisition is profitable.

Proof of Proposition 4: There are no acquisitions in the bad state at date 1. All firms know that Firm 1 will not acquire any other firm, and hence no firm has an incentive to engage in a negative NPV acquisition. But all acquisitions in the bad state at date 1 are negative NPV. Now let us turn to the good state at date 1 . As always, we will solve the model by backwards induction. 
Firm 1 acquires the largest other firm, Firm 2. It pays $C_{2}+0.5 C_{2}$. We can summarize Firm 1's behavior as follows:

Firm 1 acquires Firm 2 in the good state at date 1.

Will Firm 2 acquire Firm 5? If Firm 2 acquires Firm 5, its manager receives up to $w$. If Firm 2 does not acquire Firm 5, it is acquired by Firm 1 and its manager receives $0.5 \alpha C_{2}$. Hence, Firm 2 acquires Firm 5 if and only if $\mathrm{w}>0.5 \alpha \mathrm{C}_{2}$. It can also be easily calculated that Firm 2 wants to acquire Firms 3 and 4 under the same condition and that Firm 2's manager is indifferent between acquiring Firms 3, 4, and 5. By assumption, it resolves this indifference in favor of acquiring the smallest firm, Firm 5. We can summarize Firm 2's behavior as follows:

Firm 2 acquires Firm 5 in the good state at date 1 if and only if $\mathrm{w}>0.5 \alpha \mathrm{C}_{2}$.

Now let us turn to Firm 3. Will Firm 3 acquire Firm 5? If Firm 3 acquires Firm 5, it becomes the largest firm (other than Firm 1) and is acquired by Firm 1. Its manager receives up to $0.5 \alpha\left(C_{3}+C_{5}\right)$. If Firm 3 does not acquire Firm 5 , two situations can arise. If $w \leq 0.5 \alpha C_{2}$, Firm 1 acquires Firm 2 and Firm 3's manager receives $w$. Hence, Firm 3 acquires Firm 5 if and only if $0.5 \alpha\left(C_{3}+C_{5}\right)>w$, which is implied by $w \leq 0.5 \alpha C_{2}$. As a consequence, Firm 3 acquires Firm 5 whenever $\mathrm{w} \leq 0.5 \alpha \mathrm{C}_{2}$. If $\mathrm{w}>0.5 \alpha \mathrm{C}_{2}$, Firm 2 acquires Firm 5 if Firm 3 does not acquire Firm 5. Then Firm 1 acquires Firm 3 and Firm 3's manager receives $0.5 \alpha C_{3}$. But this is smaller than the payoff that Firm 3's manager receives if he acquires Firm 5, 0.5 $\alpha\left(C_{3}+C_{5}\right)$. Hence, Firm 3 acquires Firm 5 whenever $\mathrm{w}>0.5 \alpha \mathrm{C}_{2}$.

Will Firm 3 acquire Firm 4? If Firm 3 acquires Firm 4, it secures its independence and its manager receives up to $w$. If Firm 3 does not acquire Firm 4, two situations can arise. If $\mathrm{w} \leq 0.5 \alpha \mathrm{C}_{2}$, Firm 2 remains passive and Firm 1 acquires Firm 2. Firm 3's manager receives $w$. Hence, Firm 3 never acquires Firm 4. If $\mathrm{w}>0.5 \alpha \mathrm{C}_{2}$, Firm 2 acquires Firm 5 if Firm 3 does not acquire Firm 4. Then Firm 1 acquires Firm 3 and Firm 3's manager receives $0.5 \alpha C_{3}$. Hence, Firm 3 acquires Firm 4 if and only if $\mathrm{w}>0.5 \alpha \mathrm{C}_{3}$. Hence, Firm 3 acquires Firm 4 if and only if $\mathrm{w}>0.5 \alpha \mathrm{C}_{2}$ (recall that we are considering the parameter region $\mathrm{w}>0.5 \alpha \mathrm{C}_{2}$ ).

Whom will Firm 3 acquire - Firm 4 or Firm 5? Clearly, if $w \leq 0.5 \alpha C_{2}$, Firm 3 acquires Firm 5. Now suppose that $w>0.5 \alpha C_{2}$. If Firm 3 acquires Firm 5, its manager receives $0.5\left(0.5 \alpha\left(C_{3}+C_{5}\right)\right)+0.5\left(0.5 \alpha C_{3}\right)=0.5 \alpha C_{3}+0.25 \alpha C_{5}$. This arises because Firm 3 pays a premium for Firm 5 such that Firm 3's manager receives the average of his payoff from acquiring 
Firm 5 at a zero premium and not acquiring Firm 5. If Firm 3 acquires Firm 4, Firm 3's manager receives $0.5 w+0.5\left(0.5 \alpha C_{3}\right)=0.5 w+0.25 \alpha C_{3}$. One can easily calculate that Firm 3 prefers to acquire Firm 5 if and only if $w \leq 0.5 \alpha\left(C_{3}+C_{5}\right)$.

Hence, we can summarize Firm 3's behavior as follows:

Firm 3 acquires Firm 5 in the good state at date 1 if and only if $\mathrm{w} \leq 0.5 \alpha\left(\mathrm{C}_{3}+\mathrm{C}_{5}\right)$. Firm 3 acquires Firm 4 in the good state at date 1 if and only if $\mathrm{w}>0.5 \alpha\left(\mathrm{C}_{3}+\mathrm{C}_{5}\right)$.

Finally, will Firm 4 acquire Firm 5? If Firm 4 acquires Firm 5, Firm 1 acquires the combination of Firms 4 and 5 in the good state at date 1. Firm 4's manager receives a payoff of up to $0.5 \alpha\left(C_{4}+C_{5}\right)$. If Firm 4 does not acquire Firm 5, several situations can arise. If $\mathrm{w} \leq 0.5 \alpha\left(\mathrm{C}_{3}+\mathrm{C}_{5}\right)$, Firm 3 acquires Firm 5 and then Firm 1 acquires the combination of Firms 3 and 5. Firm 4 remains independent and its manager receives $w$. Hence, Firm 4 acquires Firm 5 if and only if $0.5 \alpha\left(C_{4}+C_{5}\right)>w$.

If $\mathrm{w}>0.5 \alpha\left(\mathrm{C}_{3}+\mathrm{C}_{5}\right)$, Firm 3 acquires Firm 4 if Firm 4 does not acquire Firm 5. To calculate the payoff of Firm 4's manager, we need to calculate the price at which Firm 3 acquires Firm 4. If Firm 3 acquires Firm 4, it remains independent and Firm 3's manager receives up to $w$. If Firm 3 does not acquire Firm 4, Firm 2 acquires Firm 5 and then Firm 1 acquires Firm 3 for a price of $C_{3}+0.5 C_{3}$. Hence, Firm 3's manager receives $0.5 \alpha C_{3}$. As a consequence, Firm 3 pays for Firm 4 a price of $\mathrm{C}_{4}+0.5 \frac{1}{\alpha}\left(\mathrm{w}-0.5 \alpha \mathrm{C}_{3}\right)$. Thus, Firm 4's manager receives 0.5 $\left(\mathrm{w}-0.5 \alpha \mathrm{C}_{3}\right)$ if Firm 4 does not acquire Firm 5. Hence, Firm 4 acquires Firm 5 if and only if $0.5 \alpha\left(\mathrm{C}_{4}+\mathrm{C}_{5}\right)>0.5\left(\mathrm{w}-0.5 \alpha \mathrm{C}_{3}\right)$ or $\mathrm{w}<\alpha\left(\mathrm{C}_{4}+\mathrm{C}_{5}\right)+0.5 \alpha \mathrm{C}_{3}$. We can summarize Firm 4 's behavior as follows.

Firm 4 acquires Firm 5 in the good state at date 1 if and only if $\mathrm{w}<0.5 \alpha\left(\mathrm{C}_{4}+\mathrm{C}_{5}\right)$ and $\mathrm{w} \in\left(0.5 \alpha\left(\mathrm{C}_{3}+\mathrm{C}_{5}\right), 0.5 \alpha \mathrm{C}_{3}+\alpha\left(\mathrm{C}_{4}+\mathrm{C}_{5}\right)\right)$.

Now let us turn to date 0 . Firm 1 will not acquire any other firm, because it has no defensive acquisition motive and a date 0 acquisition would have a negative NPV. Note also that there is no incentive for Firm 1 to acquire any other firm in order to improve its acquisition opportunities at date 1 since it can make only one acquisition. We can summarize Firm 1's behavior as follows:

Firm 1 does not acquire any other firm at date 0.

Will Firm 2 acquire Firm 5? If Firm 2 acquires Firm 5, it remains independent and its manager receives up to $2 \mathrm{w}-\alpha(1-\rho) \mathrm{C}_{5}$. If Firm 2 does not acquire Firm 5, several situations can 
arise. If $\mathrm{w}<0.5 \alpha\left(\mathrm{C}_{4}+\mathrm{C}_{5}\right)$, Firm 4 acquires Firm 5 and then Firm 1 acquires the combination of Firms 4 and 5. Hence, Firm 2 remains independent and its manager receives $2 w$, which is larger than his payoff if Firm 2 acquires Firm 5. Hence, Firm 2 does not acquire Firm 5 in this parameter region.

If $\mathrm{w} \in\left[0.5 \alpha\left(\mathrm{C}_{4}+\mathrm{C}_{5}\right), 0.5 \alpha\left(\mathrm{C}_{3}+\mathrm{C}_{5}\right)\right]$, Firm 3 acquires Firm 5 and then Firm 1 acquires the combination of Firms 3 and 5 if Firm 2 does not acquire Firm 5. Firm 2 remains independent and its manager receives $2 w$, which is larger than his payoff if Firm 2 acquires Firm 5. Hence, Firm 2 does not acquire Firm 5 in this parameter region.

If $\mathrm{w} \in\left(0.5 \alpha\left(\mathrm{C}_{3}+\mathrm{C}_{5}\right), 0.5 \alpha \mathrm{C}_{3}+\alpha\left(\mathrm{C}_{4}+\mathrm{C}_{5}\right)\right)$, Firm 4 acquires Firm 5 in the good state at date 1 and then Firm 1 acquires the combination of Firms 4 and 5 if Firm 2 does not acquire Firm 5 at date 0 . Then Firm 2 remains independent and its manager receives $2 w$. Hence, Firm 2 does not acquire Firm 5 in this parameter region.

If $\mathrm{w}>0.5 \alpha \mathrm{C}_{3}+\alpha\left(\mathrm{C}_{4}+\mathrm{C}_{5}\right)$, Firm 3 acquires Firm 4 in the good state at date 1 if Firm 2 does not acquire Firm 5 at date 0 . Will then Firm 2 acquire Firm 5 in the good state at date 1? If Firm 2 acquires Firm 5 in the good state at date 1, its manager receives up to $w$. If Firm 2 does not acquire Firm 5 in the good state at date 1, it is acquired by Firm 1 and Firm 2's manager receives $0.5 \alpha \mathrm{C}_{2}$. Hence, Firm 2 acquires Firm 5 in the good state at date 1 if and only if $\mathrm{w}>0.5 \alpha \mathrm{C}_{2}$, which is always satisfied in the parameter region $\mathrm{w}>0.5 \alpha \mathrm{C}_{3}+\alpha\left(\mathrm{C}_{4}+\mathrm{C}_{5}\right)$. Firm 2 will pay a price of $C_{5}+0.5 \frac{1}{\alpha}\left(w-0.5 \alpha C_{2}\right)$ for Firm 5 in the good state at date 1 . Hence, Firm 2's manager receives an expected payoff at date 0 of $2 \mathrm{w}-0.5 \rho\left(\mathrm{w}-0.5 \alpha \mathrm{C}_{2}\right)$ if Firm 2 does not acquire Firm 5 at date 0 . Thus, Firm 2 acquires Firm 5 at date 0 if and only if $2 \mathrm{w}-\alpha(1-\rho) \mathrm{C}_{5}>2 \mathrm{w}-0.5 \rho\left(\mathrm{w}-0.5 \alpha \mathrm{C}_{2}\right) \quad$ or $\quad \mathrm{w}>0.5 \alpha \mathrm{C}_{2}+2 \alpha \frac{1-\rho}{\rho} \mathrm{C}_{5}$. We can summarize Firm 2's behavior as follows:

Firm 2 acquires Firm 5 at date 0 if and only if $\mathrm{w} \geq 0.5 \alpha \mathrm{C}_{3}+\alpha\left(\mathrm{C}_{4}+\mathrm{C}_{5}\right)$ and at the same time $w>0.5 \alpha C_{2}+2 \alpha \frac{1-\rho}{\rho} C_{5}$. Since we have assumed in the Proposition that $0.5 \alpha C_{3}+\alpha\left(C_{4}+C_{5}\right)<0.5 \alpha C_{2}+2 \alpha \frac{1-\rho}{\rho} C_{5}$, we can conclude the following:

Firm 2 acquires Firm 5 if and only if $\mathrm{w}>0.5 \alpha \mathrm{C}_{2}+2 \alpha \frac{1-\rho}{\rho} \mathrm{C}_{5}$. 
One can also calculate under which conditions Firm 2 wants to acquire Firm 4 or Firm 3. One can easily show that Firm 2 always prefers to acquire Firm 5 rather than Firm 4 or Firm 3.

Will Firm 3 acquire Firm 5? If Firm 3 acquires Firm 5, Firm 1 acquires the combination of Firms 3 and 5 in the good state at date 1 and Firm 3's manager receives an expected payoff at date 0 of up to $w+(1-\rho)\left(w-\alpha C_{5}\right)+\rho 0.5 \alpha\left(C_{3}+C_{5}\right)$. If Firm 3 does not acquire Firm 5 , several situations can arise.

If $\mathrm{w} \leq 0.5 \alpha \mathrm{C}_{2}+2 \alpha \frac{1-\rho}{\rho} \mathrm{C}_{5}$, Firm 2 does not acquire Firm 5 at date 0 . There are several situations that can arise.

If $\mathrm{w}<0.5 \alpha\left(\mathrm{C}_{4}+\mathrm{C}_{5}\right)$, Firm 4 acquires Firm 5 in the good state at date 1 if Firm 3 does not acquire Firm 5 at date 0 . Then Firm 1 acquires the combination of Firms 4 and 5 and Firm 3 remains independent. Thus, Firm 3's manager receives $2 w$. Hence, Firm 3 acquires Firm 5 if and only if $w+(1-\rho)\left(w-\alpha C_{5}\right)+\rho 0.5 \alpha\left(C_{3}+C_{5}\right)>2 w$ or $w<-\alpha \frac{1-\rho}{\rho} C_{5}+0.5 \alpha\left(C_{3}+C_{5}\right)$.

If $\mathrm{w} \in\left[0.5 \alpha\left(\mathrm{C}_{4}+\mathrm{C}_{5}\right), 0.5 \alpha\left(\mathrm{C}_{3}+\mathrm{C}_{5}\right)\right]$, Firm 3 acquires Firm 5 in the good state at date 1 if Firm 3 does not acquire Firm 5 at date 0 . Then Firm 1 acquires the combination of Firms 3 and 5. Firm 3 pays for Firm 5 in the good state at date $1 C_{5}+0.5 \frac{1}{\alpha} 0.5 \alpha C_{5}=C_{5}+0.25 C_{5}$. Hence, Firm 3's manager receives an expected payoff of $w+(1-\rho) w+0.5 \alpha \rho\left(C_{3}+C_{5}\right)-0.25 \alpha \rho C_{5}$ at date 0 . Thus, Firm 3 acquires Firm 5 at date 0 if and only if $\mathrm{w}+(1-\rho)\left(\mathrm{w}-\alpha \mathrm{C}_{5}\right)+\rho 0.5 \alpha\left(\mathrm{C}_{3}+\mathrm{C}_{5}\right)>\mathrm{w}+(1-\rho) \mathrm{w}+0.5 \alpha \rho\left(\mathrm{C}_{3}+\mathrm{C}_{5}\right)-0.25 \alpha \rho \mathrm{C}_{5}$. One can easily show that this cannot be satisfied and hence Firm 3 does not acquire Firm 5 in this parameter region.

If $\mathrm{w} \in\left(0.5 \alpha\left(\mathrm{C}_{3}+\mathrm{C}_{5}\right), 0.5 \alpha \mathrm{C}_{3}+\alpha\left(\mathrm{C}_{4}+\mathrm{C}_{5}\right)\right)$, Firm 4 acquires Firm 5 in the good state at date 1 and then Firm 1 acquires the combination of Firms 4 and 5 if Firm 3 does not acquire Firm 5 at date 0 . Hence, Firm 3 remains independent and its manager receives $2 w$. Hence, Firm 3 acquires Firm 5 if and only if $w+(1-\rho)\left(w-\alpha C_{5}\right)+\rho 0.5 \alpha\left(C_{3}+C_{5}\right)>2 w$ or $\mathrm{w}<-\alpha \frac{1-\rho}{\rho} \mathrm{C}_{5}+0.5 \alpha\left(\mathrm{C}_{3}+\mathrm{C}_{5}\right)$. As a consequence, Firm 3 never acquires Firm 5 at date 0 in this parameter region.

If $\mathrm{w} \in\left[0.5 \alpha \mathrm{C}_{3}+\alpha\left(\mathrm{C}_{4}+\mathrm{C}_{5}\right), 0.5 \alpha \mathrm{C}_{2}+2 \alpha \frac{1-\rho}{\rho} \mathrm{C}_{5}\right]$, Firm 3 acquires Firm 4 in the good state at date 1 if Firm 3 does not acquire Firm 5 at date 0 . Firm 3 pays for Firm 4 
$\mathrm{C}_{4}+0.5 \frac{1}{\alpha}\left(\mathrm{w}-0.5 \alpha \mathrm{C}_{3}\right)$. Thus, Firm 3's manager receives $2 \mathrm{w}-0.5 \rho\left(\mathrm{w}-0.5 \alpha \mathrm{C}_{3}\right)$ if Firm 3 does not acquire Firm 5 at date 0 . Hence, Firm 3 acquires Firm 5 at date 0 if and only if $w+(1-\rho)\left(w-\alpha C_{5}\right)+\rho 0.5 \alpha\left(C_{3}+C_{5}\right)>2 w-0.5 \rho\left(w-0.5 \alpha C_{3}\right)$ or $\mathrm{w}<-2 \alpha \frac{1-\rho}{\rho} \mathrm{C}_{5}+0.5 \alpha \mathrm{C}_{3}+\alpha \mathrm{C}_{5}$. Thus, Firm 3 does not acquire Firm 5 at date 0 in this parameter region.

Finally, let us consider the parameter region in which $w>0.5 \alpha C_{2}+2 \alpha \frac{1-\rho}{\rho} C_{5}$. If Firm 3 does not acquire Firm 5 at date 0, Firm 2 acquires Firm 5 at date 0. Will then Firm 3 acquire Firm 4 in the good state at date 1? If Firm 3 acquires Firm 4 in the good state at date 1, Firm 3's manager receives up to $w$. If Firm 3 does not acquire Firm 4 in the good state at date 1, Firm 3 is acquired by Firm 1 and Firm 3's manager receives $0.5 \alpha C_{3}$. Hence, Firm 3 always acquires Firm 4 in the good state at date 1 in the parameter region we are considering. Firm 3 pays $\mathrm{C}_{4}+0.5 \frac{1}{\alpha}\left(\mathrm{w}-0.5 \alpha \mathrm{C}_{3}\right)$ for Firm 4. Hence, Firm 3's manager receives an expected payoff of $2 \mathrm{w}-0.5 \rho\left(\mathrm{w}-0.5 \alpha \mathrm{C}_{3}\right)$ at date 0 if Firm 3 does not acquire Firm 5 at date 0 . Hence, Firm 3 acquires Firm 5 at date 0 if and only if $w+(1-\rho)\left(w-\alpha C_{5}\right)+\rho 0.5 \alpha\left(C_{3}+C_{5}\right)>2 w-0.5 \rho\left(w-0.5 \alpha C_{3}\right)$ or $\mathrm{w}<-2 \alpha \frac{1-\rho}{\rho} \mathrm{C}_{5}+0.5 \alpha \mathrm{C}_{3}+\alpha \mathrm{C}_{5}$. But this is never satisfied in the parameter region we are considering and hence in this parameter region Firm 3 never acquires Firm 5 at date 0.

Will Firm 3 acquire Firm 4 at date 0? If Firm 3 acquires Firm 4 at date 0, Firm 3's manager receives up to $2 \mathrm{w}-\alpha(1-\rho) \mathrm{C}_{4}$. If Firm 3 does not acquire Firm 4 at date 0 , several situations can arise.

If $w \leq 0.5 \alpha C_{2}+2 \alpha \frac{1-\rho}{\rho} C_{5}$, Firm 2 does not acquire Firm 5 at date 0.

If $\mathrm{w}<0.5 \alpha\left(\mathrm{C}_{4}+\mathrm{C}_{5}\right)$, Firm 4 acquires Firm 5 in the good state at date 1 if Firm 3 does not acquire Firm 4 at date 0. Then Firm 1 acquires the combination of Firms 4 and 5. Hence, Firm 3 remains independent and its manager receives $2 w$. But this is larger than the payoff to Firm 3's manager if Firm 3 acquires Firm 4 at date 0, and hence Firm 3 does not acquire Firm 4 at date 0 in this parameter region. 
If $\mathrm{w} \in\left[0.5 \alpha\left(\mathrm{C}_{4}+\mathrm{C}_{5}\right), 0.5 \alpha\left(\mathrm{C}_{3}+\mathrm{C}_{5}\right)\right]$, Firm 4 remains passive and Firm 3 acquires Firm 5 in the good state at date 1 and then Firm 1 acquires the combination of Firms 3 and 5 if Firm 3 does not acquire Firm 4 at date 0 . Firm 3 pays $C_{5}+0.5 \frac{1}{\alpha} 0.5 \alpha C_{5}=C_{5}+0.25 C_{5}$ for Firm 5 in the good state at date 1 and hence its manager receives an expected payoff of $w+(1-\rho) w+\rho 0.5 \alpha\left(C_{3}+C_{5}\right)-\rho 0.25 \alpha C_{5}$ at date 0 if Firm 3 does not acquire Firm 4 at date 0. As a consequence, Firm 3 acquires Firm 4 at date 0 if and only if $2 \mathrm{w}-\alpha(1-\rho) \mathrm{C}_{4}>\mathrm{w}+(1-\rho) \mathrm{w}+\rho 0.5 \alpha\left(\mathrm{C}_{3}+\mathrm{C}_{5}\right)-\rho 0.25 \alpha \mathrm{C}_{5}$ or $\mathrm{w}>\alpha \frac{1-\rho}{\rho} \mathrm{C}_{4}+0.5 \alpha \mathrm{C}_{3}+0.25 \alpha \mathrm{C}_{5}$. But this is never satisfied in the parameter region we are considering, and hence Firm 3 never acquires Firm 4 at date 0 in this parameter region.

If $\mathrm{w} \in\left(0.5 \alpha\left(\mathrm{C}_{3}+\mathrm{C}_{5}\right), 0.5 \alpha \mathrm{C}_{3}+\alpha\left(\mathrm{C}_{4}+\mathrm{C}_{5}\right)\right)$, Firm 4 acquires Firm 5 in the good state at date 1 if Firm 3 does not acquire Firm 4 at date 0. Then Firm 1 acquires the combination of Firms 4 and 5 and hence Firm 3 remains independent. Thus, its manager receives $2 w$. But this is larger than the payoff to Firm 3's manager if Firm 3 acquires Firm 4 at date 0, and hence Firm 3 does not acquire Firm 4 at date 0 in this parameter region.

If $\mathrm{w} \in\left[0.5 \alpha \mathrm{C}_{3}+\alpha\left(\mathrm{C}_{4}+\mathrm{C}_{5}\right), 0.5 \alpha \mathrm{C}_{2}+2 \alpha \frac{1-\rho}{\rho} \mathrm{C}_{5}\right]$, Firm 3 acquires Firm 4 in the good state at date 1 if Firm 3 does not acquire Firm 4 at date 0 . Firm 3 pays $C_{4}+0.5 \frac{1}{\alpha}\left(w-0.5 \alpha C_{3}\right)$ for Firm 4 in the good state at date 1. Hence, Firm 3's manager receives an expected payoff of $2 \mathrm{w}-\rho 0.5\left(\mathrm{w}-0.5 \alpha \mathrm{C}_{3}\right)$ at date 0 if Firm 3 does not acquire Firm 4 at date 0 . As a consequence, Firm 3 acquires Firm 4 at date 0 if and only if $2 w-\alpha(1-\rho) C_{4}>2 w-\rho 0.5\left(w-0.5 \alpha C_{3}\right)$ or $\mathrm{w}>0.5 \alpha \mathrm{C}_{3}+2 \alpha \frac{1-\rho}{\rho} \mathrm{C}_{4}$. Since we have assumed in the Proposition that $0.5 \alpha C_{2}+2 \alpha \frac{1-\rho}{\rho} C_{5}<0.5 \alpha C_{3}+2 \alpha \frac{1-\rho}{\rho} C_{4}$, Firm 3 does not acquire Firm 4 at date 0 in this parameter region.

Finally, let us consider the parameter region in which $w>0.5 \alpha C_{2}+2 \alpha \frac{1-\rho}{\rho} C_{5}$. If Firm 3 does not acquire Firm 4 at date 0, Firm 2 acquires Firm 5 at date 0. Will then Firm 3 acquire Firm 4 in the good state at date 1? If Firm 3 acquires Firm 4 in the good state at date 1, Firm 3's manager receives up to $w$. If Firm 3 does not acquire Firm 4 in the good state at date 1, Firm 3 is ac- 
quired by Firm 1 and Firm 3's manager receives $0.5 \alpha C_{3}$. Hence, Firm 3 always acquires Firm 4 in the good state at date 1 . Firm 3 pays $\mathrm{C}_{4}+0.5 \frac{1}{\alpha}\left(\mathrm{w}-0.5 \alpha \mathrm{C}_{3}\right)$ and Firm 3's manager receives an expected payoff of $2 \mathrm{w}-0.5 \rho\left(\mathrm{w}-0.5 \alpha \mathrm{C}_{3}\right)$ at date 0 if Firm 3 does not acquire Firm 4 at date 0. Hence, Firm 3 acquires Firm 4 at date 0 if and only if $2 w-\alpha(1-\rho) C_{4}>2 w-\rho 0.5\left(w-0.5 \alpha C_{3}\right)$ or $w>2 \alpha \frac{1-\rho}{\rho} C_{4}+0.5 \alpha C_{3}$. Since we have assumed in the Proposition that $0.5 \alpha C_{2}+2 \alpha \frac{1-\rho}{\rho} C_{5}<0.5 \alpha C_{3}+2 \alpha \frac{1-\rho}{\rho} C_{4}$, Firm 3 acquires Firm 4 at date 0 in this parameter region if and only if $w>0.5 \alpha C_{3}+2 \alpha \frac{1-\rho}{\rho} C_{4}$.

We can summarize Firm 3's behavior as follows:

Firm 3 acquires Firm 5 at date 0 if and only if $\mathrm{w}<-\alpha \frac{1-\rho}{\rho} \mathrm{C}_{5}+0.5 \alpha\left(\mathrm{C}_{3}+\mathrm{C}_{5}\right)$. Firm 3 acquires Firm 4 at date 0 if and only if $\mathrm{w}>0.5 \alpha \mathrm{C}_{3}+2 \alpha \frac{1-\rho}{\rho} \mathrm{C}_{4}$.

Finally, let us analyze under which conditions Firm 4 acquires Firm 5 at date 0. If Firm 4 acquires Firm 5 at date 0, Firm 1 acquires the combination of Firms 4 and 5 in the good state at date 1. Hence, Firm 4's manager receives an expected payoff of up to $\mathrm{w}+(1-\rho)\left(\mathrm{w}-\alpha \mathrm{C}_{5}\right)+0.5 \rho \alpha\left(\mathrm{C}_{4}+\mathrm{C}_{5}\right)$ at date 0 . If Firm 4 does not acquire Firm 5 at date 0 , several situations can arise.

If $\mathrm{w}<-\alpha \frac{1-\rho}{\rho} \mathrm{C}_{5}+0.5 \alpha\left(\mathrm{C}_{3}+\mathrm{C}_{5}\right)$, Firm 3 acquires Firm 5 at date 0 . Then Firm 1 acquires the combination of Firms 3 and 5 in the good state at date 1. Firm 4 remains independent and its manager receives $2 w$. Hence, Firm 4 acquires Firm 5 at date 0 if and only if $\mathrm{w}+(1-\rho)\left(\mathrm{w}-\alpha \mathrm{C}_{5}\right)+0.5 \rho \alpha\left(\mathrm{C}_{4}+\mathrm{C}_{5}\right)>2 \mathrm{w}$ or $\mathrm{w}<-\alpha \frac{1-\rho}{\rho} \mathrm{C}_{5}+0.5 \alpha\left(\mathrm{C}_{4}+\mathrm{C}_{5}\right)$.

If $\mathrm{w} \in\left[-\alpha \frac{1-\rho}{\rho} \mathrm{C}_{5}+0.5 \alpha\left(\mathrm{C}_{3}+\mathrm{C}_{5}\right), 0.5 \alpha\left(\mathrm{C}_{4}+\mathrm{C}_{5}\right)\right)$, Firm 4 acquires Firm 5 in the good state at date 1 and then Firm 1 acquires the combination of Firms 4 and 5 if Firm 4 does not acquire Firm 5 at date 0 . Firm 4 pays $C_{5}+0.5 \frac{1}{\alpha}\left(0.5 \alpha\left(C_{4}+C_{5}\right)-w\right)$ for Firm 5 in the good state at date 1. Thus, Firm 4's manager receives an expected payoff of $w+(1-\rho) w+\rho\left(0.5 \alpha\left(C_{4}+C_{5}\right)-0.5\left(0.5 \alpha\left(C_{4}+C_{5}\right)-w\right)\right)$ 
or $w+(1-\rho) w+\rho\left(0.25 \alpha\left(C_{4}+C_{5}\right)+0.5 w\right)$ at date 0 if Firm 4 does not acquire Firm 5 at date 0 . Hence, Firm 4 acquires Firm 5 at date 0 if and only if $w+(1-\rho)\left(w-\alpha C_{5}\right)+0.5 \rho \alpha\left(C_{4}+C_{5}\right)>w+(1-\rho) w+\rho\left(0.25 \alpha\left(C_{4}+C_{5}\right)+0.5 w\right) \quad$ or $\mathrm{w}<-2 \alpha \frac{1-\rho}{\rho} \mathrm{C}_{5}+0.5 \alpha\left(\mathrm{C}_{4}+\mathrm{C}_{5}\right)$. But this is never satisfied in the parameter region we are considering, and hence in this parameter region Firm 4 does not acquire Firm 5 at date 0.

If $\mathrm{w} \in\left[0.5 \alpha\left(\mathrm{C}_{4}+\mathrm{C}_{5}\right), 0.5 \alpha\left(\mathrm{C}_{3}+\mathrm{C}_{5}\right)\right]$, Firm 3 acquires Firm 5 in the good state at date 1 if Firm 4 does not acquire Firm 5 at date 0. Then Firm 1 acquires the combination of Firms 3 and 5. Firm 4 remains independent and its manager receives $2 w$. Hence, Firm 4 acquires Firm 5 at date 0 if and only if $w+(1-\rho)\left(w-\alpha C_{5}\right)+0.5 \rho \alpha\left(C_{4}+C_{5}\right)>2 w$ or $w<-\alpha \frac{1-\rho}{\rho} C_{5}+0.5 \alpha\left(C_{4}+C_{5}\right)$. But this is never satisfied in the parameter region we are considering, and hence Firm 4 does not acquire Firm 5 at date 0 in this parameter region.

If $\mathrm{w} \in\left(0.5 \alpha\left(\mathrm{C}_{3}+\mathrm{C}_{5}\right), 0.5 \alpha \mathrm{C}_{3}+\alpha\left(\mathrm{C}_{4}+\mathrm{C}_{5}\right)\right)$, Firm 4 acquires Firm 5 in the good state at date 1 and then Firm 1 acquires the combination of Firms 4 and 5 if Firm 4 does not acquire Firm 5 at date 0 . If Firm 4 acquires Firm 5 in the good state at date 1, Firm 4's manager receives up to $0.5 \alpha\left(C_{4}+C_{5}\right)$, because Firm 1 will acquire the combination of Firms 4 and 5 . If Firm 4 does not acquire Firm 5 in the good state at date 1 , Firm 3 acquires Firm 4 for $C_{4}+0.5 \frac{1}{\alpha}\left(w-0.5 \alpha C_{3}\right)$ and Firm 4's manager receives $0.5\left(\mathrm{w}-0.5 \alpha \mathrm{C}_{3}\right)$. As a consequence, Firm 4 pays $\mathrm{C}_{5}+0.5 \frac{1}{\alpha}\left(0.5 \alpha\left(\mathrm{C}_{4}+\mathrm{C}_{5}\right)-0.5\left(\mathrm{w}-0.5 \alpha \mathrm{C}_{3}\right)\right)$ for Firm 5 in the good state at date 1. Hence, Firm 4's manager an receives expected payoff of $w+(1-\rho) w+\rho\left(0.5 \alpha\left(C_{4}+C_{5}\right)-0.5\left(0.5 \alpha\left(C_{4}+C_{5}\right)-0.5\left(w-0.5 \alpha C_{3}\right)\right)\right.$ at date 0 if Firm 4 does not acquire Firm 5 at date 0 . Hence, Firm 4 acquires Firm 5 at date 0 if and only if $\mathrm{w}+(1-\rho)\left(\mathrm{w}-\alpha \mathrm{C}_{5}\right)+0.5 \rho \alpha\left(\mathrm{C}_{4}+\mathrm{C}_{5}\right)>\mathrm{w}+(1-\rho) \mathrm{w}+\rho\left(0.25 \alpha\left(\mathrm{C}_{4}+\mathrm{C}_{5}\right)+0.25 \mathrm{w}\right.$ $\left.-0.125 \alpha \mathrm{C}_{3}\right)$

as can be seen after some algebraic manipulation, or $\mathrm{w}<-4 \alpha \frac{1-\rho}{\rho} \mathrm{C}_{5}+\alpha\left(\mathrm{C}_{4}+\mathrm{C}_{5}\right)+0.5 \alpha \mathrm{C}_{3}$. But the Proposition assumed that $-4 \alpha \frac{1-\rho}{\rho} C_{5}+\alpha\left(C_{4}+C_{5}\right)+0.5 \alpha C_{3} \leq 0.5 \alpha\left(C_{3}+C_{5}\right)$ and hence Firm 4 does not acquire Firm 5 at date 0 in the parameter region we are considering. 
If $\mathrm{w} \in\left[0.5 \alpha \mathrm{C}_{3}+\alpha\left(\mathrm{C}_{4}+\mathrm{C}_{5}\right), 0.5 \alpha \mathrm{C}_{2}+2 \alpha \frac{1-\rho}{\rho} \mathrm{C}_{5}\right]$, Firm 3 acquires Firm 4 in the good state at date 1 if Firm 4 does not acquire Firm 5 at date 0 . Firm 3 pays $C_{4}+0.5 \frac{1}{\alpha}\left(w-0.5 \alpha C_{3}\right)$ for Firm 4 in the good state at date 1. Hence, Firm 4's manager receives an expected payoff of $\mathrm{w}+(1-\rho) \mathrm{w}+0.5 \rho\left(\mathrm{w}-0.5 \alpha \mathrm{C}_{3}\right)$ at date 0 if Firm 4 does not acquire Firm 5 at date 0 . As a consequence, Firm 4 acquires Firm 5 at date 0 if and only if $\mathrm{w}+(1-\rho)\left(\mathrm{w}-\alpha \mathrm{C}_{5}\right)+0.5 \rho \alpha\left(\mathrm{C}_{4}+\mathrm{C}_{5}\right)>\mathrm{w}+(1-\rho) \mathrm{w}+0.5 \rho\left(\mathrm{w}-0.5 \alpha \mathrm{C}_{3}\right) \quad$ or $\mathrm{w}<-2 \alpha \frac{1-\rho}{\rho} \mathrm{C}_{5}+\alpha\left(\mathrm{C}_{4}+\mathrm{C}_{5}\right)+0.5 \alpha \mathrm{C}_{3}$. But this is not satisfied in the parameter region we are considering and hence Firm 4 does not acquire Firm 5 at date 0 in this parameter region.

If $w \in\left[0.5 \alpha C_{2}+2 \alpha \frac{1-\rho}{\rho} C_{5}, 0.5 \alpha C_{3}+2 \alpha \frac{1-\rho}{\rho} C_{4}\right]$, Firm 2 acquires Firm 5 at date 0 if Firm 4 does not acquire Firm 5 at date 0. Will then Firm 3 acquire Firm 4 at date 0? If Firm 3 acquires Firm 4 at date 0, Firm 3's manager receives up to $2 \mathrm{w}-\alpha(1-\rho) \mathrm{C}_{4}$. If Firm 3 does not acquire Firm 4 at date 0, will Firm 3 acquire Firm 4 in the good state at date 1? If Firm 3 acquires Firm 4 in the good state at date 1, Firm 3's manager receives up to $w$. If Firm 3 does not acquire Firm 4 in the good state at date 1, Firm 3 is acquired by Firm 1 and Firm 3's manager receives $0.5 \alpha C_{3}$. Hence, Firm 3 always acquires Firm 4 in the good state at date 1 in this parameter region if it does not do so at date 0 . Firm 3 pays $\mathrm{C}_{4}+0.5 \frac{1}{\alpha}\left(\mathrm{w}-0.5 \alpha \mathrm{C}_{3}\right)$ for Firm 4 in the good state at date 1. Hence, Firm 3's manager receives an expected payoff of $2 w-0.5 \rho\left(w-0.5 \alpha C_{3}\right)$ at date 0 if Firm 3 does not acquire Firm 4 at date 0 (but in the good state at date 1). Thus, Firm 3 acquires Firm 4 at date 0 if and only if $2 w-\alpha(1-\rho) C_{4}>2 w-0.5 \rho\left(w-0.5 \alpha C_{3}\right)$ or $\mathrm{w}>0.5 \alpha \mathrm{C}_{3}+2 \alpha \frac{1-\rho}{\rho} \mathrm{C}_{4}$. Since this is never satisfied in the parameter region we are considering, Firm 3 never acquires Firm 4 at date 0, but always in the good state at date 1. As a consequence, Firm 4's manager receives an expected payoff of $w+(1-\rho) w+0.5 \rho\left(w-0.5 \alpha C_{3}\right)$ at date 0 if Firm 4 does not acquire Firm 5 at date 0. Hence, Firm 4 acquires Firm 5 at date 0 if and only if $w+(1-\rho)\left(w-\alpha C_{5}\right)+0.5 \rho \alpha\left(C_{4}+C_{5}\right)>w+(1-\rho) w+0.5 \rho\left(w-0.5 \alpha C_{3}\right)$ or $\mathrm{w}<-2 \alpha \frac{1-\rho}{\rho} \mathrm{C}_{5}+\alpha\left(\mathrm{C}_{4}+\mathrm{C}_{5}\right)+0.5 \alpha \mathrm{C}_{3}$. But this is never satisfied in the parameter region we are considering, and hence Firm 4 never acquires Firm 5 at date 0 in this parameter region. 
Finally, let us consider the parameter region in which $\mathrm{w}>0.5 \alpha \mathrm{C}_{3}+2 \alpha \frac{1-\rho}{\rho} \mathrm{C}_{4}$. In this parameter region, Firm 3 acquires Firm 4 at date 0 if Firm 4 does not acquire Firm 5 at date 0. If Firm 3 acquires Firm 4 at date 0, Firm 3's manager receives up to $2 w-\alpha(1-\rho) C_{4}$. If Firm 3 does not acquire Firm 4 at date 0, Firm 2 acquires Firm 5 at date 0. Will then Firm 3 acquire Firm 4 in the good state at date 1? If Firm 3 acquires Firm 4 in the good state at date 1, Firm 3's manager receives up to $w$. If Firm 3 does not acquire Firm 4 in the good state at date 1, Firm 3 is acquired by Firm 1 and Firm 3's manager receives $0.5 \alpha C_{3}$. Hence, Firm 3 acquires Firm 4 in the good state at date 1 if and only if $w>0.5 \alpha C_{3}$, which is always satisfied in the parameter region we are considering. Firm 3 pays $C_{4}+0.5 \frac{1}{\alpha}\left(w-0.5 \alpha C_{3}\right)$ for Firm 4 in the good state at date 1 . Thus, Firm 3's manager receives an expected payoff of $2 w-0.5 \rho\left(w-0.5 \alpha C_{3}\right)$ at date 0 if Firm 3 does not acquire Firm 4 at date 0 (but instead in the good state at date 1). Hence, Firm 3 acquires Firm 4 at date 0 if and only if $2 w-\alpha(1-\rho) C_{4}>2 w-0.5 \rho\left(w-0.5 \alpha C_{3}\right)$ or $w>2 \alpha \frac{1-\rho}{\rho} C_{4}+0.5 \alpha C_{3}$, which was assumed to hold. Hence, Firm 3 always acquires Firm 4 at date 0 . It will pay a price of $C_{4}+0.5 \frac{1}{\alpha}\left(2 w-\alpha(1-\rho) C_{4}-2 w+0.5 \rho\left(w-0.5 \alpha C_{3}\right)\right)$. As a consequence, Firm 4's manager receives $0.5\left(-\alpha(1-\rho) C_{4}+0.5 \rho\left(w-0.5 \alpha C_{3}\right)\right)$ at date 0 if Firm 4 does not acquire Firm 5 at date 0 . Hence, Firm 4 acquires Firm 5 at date 0 if and only if $w+(1-\rho)\left(w-\alpha C_{5}\right)+0.5 \rho \alpha\left(C_{4}+C_{5}\right)>0.5\left(-\alpha(1-\rho) C_{4}+0.5 \rho\left(w-0.5 \alpha C_{3}\right)\right)$ or $w>\frac{\alpha(1-\rho) C_{5}}{2-\rho-0.25 \rho}-\frac{0.5 \alpha \rho\left(C_{4}+C_{5}\right)}{2-\rho-0.25 \rho}-\frac{0.5 \alpha(1-\rho) C_{4}}{2-\rho-0.25 \rho}-\frac{0.125 \alpha \rho C_{3}}{2-\rho-0.25 \rho}$. But this is always satisfied in the parameter region that we are considering, and hence Firm 4 always acquires Firm 5 at date 0 in this parameter region.

We can summarize Firm 4's behavior as follows:

Firm 4 acquires Firm 5 at date 0 if and only if $w<-\alpha \frac{1-\rho}{\rho} C_{5}+0.5 \alpha\left(C_{4}+C_{5}\right)$ and $\mathrm{w}>0.5 \alpha \mathrm{C}_{3}+2 \alpha \frac{1-\rho}{\rho} \mathrm{C}_{4}$.

To complete the proof of the Proposition, we have to calculate the equilibrium merger activity arising from the firms' behavior summarized in the statements in italics. It is easy to verify (keeping in mind that Firm 4 moves first, Firm 3 second, Firm 2 third, and Firm 1 last at each date) that 
the merger activity as described in the Proposition is the only equilibrium merger activity. Note that after Firm 4 acquires Firm 5 or Firm 3 acquires Firm 5, Firm 1 acquires the combination of Firms 4 and 5 or Firms 3 and 5. If $w \in\left[0.5 \alpha C_{3}+\alpha\left(C_{4}+C_{5}\right), 0.5 \alpha C_{2}+2 \alpha \frac{1-\rho}{\rho} C_{5}\right]$, Firm 3 acquires Firm 4 in the good state at date 1. Will then Firm 2 acquire Firm 5 in the good state at date 1? If Firm 2 acquires Firm 5, Firm 2's manager receives a payoff of $w$. If Firm 2 does not acquire Firm 5, it is acquired by Firm 1 and Firm 2's manager receives a payoff of $0.5 \alpha C_{2}$. Hence, Firm 2 acquires Firm 5 after Firm 3 acquires Firm 4 in the good state at date 1. If $w \in\left(0.5 \alpha C_{2}+2 \alpha \frac{1-\rho}{\rho} C_{5}, 0.5 \alpha C_{3}+2 \alpha \frac{1-\rho}{\rho} C_{4}\right]$, Firm 2 acquires Firm 5 at date 0 . Will then Firm 3 acquire Firm 4 in the good state at date 1? If Firm 3 acquires Firm 4, its manager receives a payoff of up to $w$. If Firm 3 does not acquire Firm 4, it is acquired by Firm 1 and its manager receives a payoff of $0.5 \alpha C_{3}$. Hence, Firm 3 acquires Firm 4 in the good state at date 1 after Firm 2 acquires Firm 5 at date 0 . If $w>0.5 \alpha C_{3}+2 \alpha \frac{1-\rho}{\rho} C_{4}$, Firm 4 acquires Firm 5 at date 0 . In this case one can show that the acquisition is unprofitable for sufficiently high $w$. The reason is that the alternative, being acquired by Firm 3 at date 0 , is more profitable than this acquisition if the premium paid by Firm 3 is sufficiently high, and the premium is increasing in $w$ (see the calculation of the price at which Firm 3 would acquire Firm 4 at date 0 if Firm 4 did not acquire Firm 5 at date 0$)$. 


\section{References}

Agrawal, Anup, and Gershon N. Mandelker (1987), "Managerial Incentives and Corporate Investment and Financing Decisions,” Journal of Finance 42(4): 823-837.

Ambrose, Brent W., and William L. Megginson (1992), “The Role of Asset Structure, Ownership Structure, and Takeover Defenses in Determining Acquisition Likelihood,” Journal of Financial and Quantitative Analysis 27(4): 575-589.

Amihud, Yakov and Baruch Lev (1981), "Risk Reduction as Managerial Motive for Conglomerate Mergers,” Bell Journal of Economics 12(2): 823-837.

Andrade, Gregor, Mark Mitchell, and Erik Stafford (2001), "New Evidence and Perspectives on Mergers”, Journal of Economic Perspectives 15(2): 103-120.

Ang, James S., and Yingmei Cheng (2003), "Direct Evidence on the Market-Driven Acquisitions Theory”, working paper, Florida State University.

Andrade, Gregor, and Erik Stafford (2004), “Investigating the Economic Role of Mergers”, Journal of Corporate Finance 10(1): 1-36.

Asquith, Paul, Robert Bruner, and David Mullins (1987), "Merger Returns And The Form Of Financing,” mimeo.

Baker, J. (1997), “Contemporary Merger Analysis,” George Mason Law Review 5(3): 347-361.

Banerjee, Ajeyo, and James Owers (1992), “Wealth Reduction In White Knight Bids,” Financial Management 21(3): 48-57.

Baumol, William (1959), Business Behavior, Value, and Growth, New York, New York: Macmillan.

Berry, Steven and Ariel Pakes (1993), "Some Applications and Limitations of Recent Advances in Empirical I.O.: Merger Analysis,” American Economic Review 83: 247-252. 
Bliss, Richard, and Richard Rosen (2001), “CEO Compensation and Bank Mergers,” Journal of Financial Economics 61(1): 107-138.

Bradley, Michael, Anand Desai, and E. Han Kim (1988), "Synergistic Gains From Corporate Acquisitions And Their Division Between the Stockholders Of Target and Acquiring Firms,” Journal of Financial Economics 21 (1): 3-40.

Byrd, John, and Kent Hickman (1992), “Do Outside Directors Monitor Managers?: Evidence From Tender Offer Bids,” Journal of Financial Economics 32 (2): 195-221.

Comment, Robert, and G. William Schwert (1995), "Poison or Placebo? Evidence on the Deterrence and Wealth Effects of Modern Antitakeover Measures", Journal of Financial Economics 39 (1): 3-43.

Dong, Ming, David Hirshleifer, Scott Richardson, and Siew Hong Teoh (2003), "Does Investor Misvaluation Drive the Takeover Market?”, working paper, Ohio State University.

Epstein, Roy and Daniel Rubinfeld (2001), "Merger Simulation: A Simplified Approach with New Applications,” University of California, Berkeley, Working Paper \#E01-309.

Ericson, Richard and Ariel Pakes (1995), “An Alternative Theory of Firm and Industry Dynamics,” Review of Economic Studies 62: 53-82.

Gilson, Ronald J., and Bernard S. Black (1995), The Law And Finance Of Corporate Acquisitions, Westbury, New York: The Foundation Press, $2^{\text {nd }}$ edition.

Gilson, Stuart C. (1989), “Management Turnover and Financial Distress”, Journal of Financial Economics 25(2): 241-262.

Gort, Michael (1969), “An Economic Disturbance Theory of Mergers,” Quarterly Journal of Economics 83(4): 624-642.

Gowrisankaran, Gautam (1999), “A Dynamic Model of Endogenous Horizontal Mergers,” Rand Journal of Economics 30: 56-83.

Gowrisankaran, Gautam and Thomas J. Holmes (2004), "Mergers and the Evolution of Industry Concentration: Results from the Dominant-Firm Model,” RAND Journal of Economics 35(3): 561-582.

Harford, Jarrad (2004), “What drives merger waves?”, forthcoming in Journal of Financial Economics.

Harris, Ellie (1994), "Why One Firm Is The Target and The Other The Bidder In Single-Bidder, 
Synergistic Takeovers,” Journal of Business 67 (2): 263-280.

Hart, Oliver, and John Moore (1995), "Debt and Seniority: An Analysis of the Role of Hard Claims in Constraining Management”, American Economic Review 85(3): 567-585.

Hasbrouck, Joel (1985), “The Characteristics of Takeover Targets. Q and Other Measures,” Journal of Banking and Finance 9(3): 351-362.

Jarrell, Gregg, James Brickley, and Jeffrey Netter (1988), “The Market for Corporate Control: The Empirical Evidence Since 1980,” Journal of Economic Perspectives 2(1): 49-68.

Jennings, Robert, and Michael Mazzeo (1991), "Stock Price Movements Around Acquisition Announcements And Management’s Response,” Journal of Business 64(2): 139-163.

Jensen, Michael, and Richard Ruback (1983), “The Market for Corporate Control: The Scientific Evidence,” Journal of Financial Economics 11(1-4): 5-50.

Jensen, Michael C. (1986), “Agency costs of free cash flow, corporate finance, and takeovers”, American Economic Review 76(2): 323-329.

Jensen, Michael C. (1993), "The modern industrial revolution, exit, and the failure of internal control systems”, Journal of Finance 48(3): 831-880.

Jovanovic, Boyan, and Serguey Braguinsky (2004), "Bidder Discounts and Target Premia in Takeovers”, American Economic Review 94(1): 46-56.

Jovanovic, Boyan, and Peter Rousseau (2002), “The Q-Theory of Mergers”, American Economic Review 92(2): 198-204.

Kahl, Matthias, and Richard Rosen (2002), “Acquirer Size, Abnormal Returns, and The Managerial View of Mergers”, unpublished working paper, University of California, Los Angeles.

Kahl, Matthias, and Rossen Valkanov (2004), “Mega-Mergers and Stock Market Booms”, working paper, University of North Carolina at Chapel Hill.

Kamien, Morton and Israel Zang (1990), “The Limits of Monopolization through Acquisition,” Quarterly Journal of Economics 105: 465-499.

Lambrecht, Bart M. (2004), “The timing and terms of mergers motivated by economies of scale”, Journal of Financial Economics 72(1): 41-62.

Lewellen, Wilbur, Claudio Loderer, and Ahron Rosenfeld (1985), "Merger Decisions And Executive Stock Ownership In Acquiring Firms," Journal of Accounting and Economics 7 (1-3): 209- 
231.

Loderer, Claudio, and Kenneth Martin (1997), "Executive Stock Ownership and Performance: Tracking Faint Traces,” Journal of Financial Economics 45(2): 223-255.

Louis, Henock (2004), "The Cost of Using Bank Mergers as Defensive Mechanisms against Takeover Threats”, The Journal of Business 77(2): 295-310.

Malmendier, Ulrike, and Geoffrey Tate (2003), "Who Makes Acquisitions? CEO Overconfidence and the Market’s Reaction”, working paper, Stanford University.

Marris, Robin (1964), The Economic Theory of Managerial Capitalism, Glenncoe, Illinois: Free Press.

May, Don (1995), “Do Managerial Motives Influence Firm Risk Reduction Strategies?,” Journal of Finance 50(4): 1291-1308.

McCardle, Kevin F., and S. Viswanathan (1994), "The Direct Entry versus Takeover Decision and Stock Price Performance around Takeovers”, Journal of Business 67(1): 1-43.

Mitchell, Mark L., and J. Harold Mulherin (1996), “The Impact Of Industry Shocks On Takeover And Restructuring Activity,” Journal of Financial Economics 41(2): 193-229.

Moeller, Sara B., Frederik P. Schlingemann, and Rene M. Stulz (2004), "Do shareholders of acquiring firms gain from acquisitions?” forthcoming in Journal of Financial Economics.

Morck, Randall, Andrei Shleifer, and Robert W. Vishny (1988), "Characteristics of Targets of Hostile and Friendly Takeovers", in: Alan J. Auerbach, editor, Corporate Takeovers: Causes and Consequences, Chicago, Illinois: University of Chicago Press: 101-129.

Morck, Randall, Andrei Shleifer, and Robert Vishny (1990), “Do Managerial Objectives Drive Bad Acquisitions?,” Journal of Finance 45(1): 31-48.

Morellec, Erwan, and Alexei Zhdanov (2004), “The dynamics of mergers and acquisitions”, forthcoming in Journal of Financial Economics.

Palepu, Krishna G. (1986), "Predicting Takeover Targets: A Methodological and Empirical Analysis,” Journal of Accounting and Economics 8(1): 3-35.

Peters, Craig (2003), "Evaluating the Performance of Merger Simulation: Evidence from the U.S. Airline Industry," Center for the Study of Industrial Organization, Northwestern University, Working Paper \#0032. 
Rau, Raghavendra P., and Theo Vermaelen (1998), "Glamour, Value, and the Post-acquisition Performance of Acquiring Firms”, Journal of Financial Economics 49(2): 223-253.

Rhodes-Kropf, Matthew, David T. Robinson, and S. Viswanathan (2004), "Valuation Waves and Merger Activity: The Empirical Evidence”, forthcoming, Journal of Financial Economics.

Rhodes-Kropf, Matthew, and S. Viswanathan (2004), “Market Valuation and Merger Waves”, The Journal of Finance 59(6): 2685-2718.

Roll, Richard (1986), “The Hubris Hypothesis Of Corporate Takeovers,” Journal of Business 59(2): 197-216.

Ruback, Richard (1988), “An Overview of Takeover Defenses,” in Alan J. Auerbach, editor, Mergers and Acquisitions, University of Chicago Press, Chicago: 69-85.

Rubin, Paul H. (1973), “The Expansion of Firms,” Journal of Political Economy 81(4): 936-949.

Schwert, G. William (2000), "Hostility in Takeovers: In the Eyes of the Beholder," Journal of Finance, 55: 2599-2640.

Servaes, Henri (1991), “Tobin’s Q And the Gains From Takeovers,” Journal of Finance 46(1): 409-419.

Shleifer, Andrei, and Robert W. Vishny (1989), “Management Entrenchment: The Case of Manager-Specific Investments,” Journal of Financial Economics 25(1): 123-139.

Shleifer, Andrei, and Robert W. Vishny (2003), “Stock Market Driven Acquisitions”, Journal of financial Economics 70(3): 295-311.

Toxvaerd, Flavio (2004), “Strategic Merger Waves: A Theory of Musical Chairs”, working paper, Hebrew University of Jerusalem.

Varaiya, Nikhil, and Kenneth Ferris, 1987, “Overpaying In Corporate Takeovers: The Winner's Curse,” Financial Analysts’ Journal: 64-70.

Weston, J. Fred, Kwang S. Chung, and Juan A. Siu (1998), Takeovers, Restructuring, and Corporate Governance, Upper Saddle River, NJ, Prentice Hall.

You, Victor, Richard Caves, Michael Smith, and James Henry (1986), "Mergers and Bidders' Wealth: Managerial And Strategic Factors,” in: Lacy Glenn Thomas, III (ed.), The Economics of Strategic Planning. Essays In Honor Of Joel Dean, Lexington Books, 201-221. 
Figure 1: Timing in the Three Firm Model

Date 0

Firms learn parameters of the model.

Firm 1 decides whether to make an acquisition offer, and, if so, which Firm to acquire.

Target firm shareholders decide whether to accept the acquisition offer.

Firm 2, if it has not been acquired, decides whether to make an acquisition offer, and, if so, which Firm to acquire.

Target firm shareholders decide whether to accept the acquisition offer.

Date 1

Firms learn state of nature: either good or bad.

In both states, repeat acquisition moves as at date 0 . 
Figure 2: Timing in the Five Firm Model

Date 0

Firms learn parameters of the model.

Firm 4 decides whether to make an acquisition offer,

and, if so, which Firm to acquire.

Target firm shareholders decide whether to accept the acquisition offer.

Firm 3 decides whether to make an acquisition offer, and, if so, which Firm to acquire.

Target firm shareholders decide whether to accept the acquisition offer.

Firm 2 decides whether to make an acquisition offer, and, if so, which Firm to acquire.

Target firm shareholders decide whether to accept the acquisition offer.

Firm 1 decides whether to make an acquisition offer, and, if so, which Firm to acquire.

Target firm shareholders decide whether to accept the acquisition offer.

Date 1

Firms learn state of nature: either good or bad.

In both states, repeat acquisition moves as at date 0. Firms get to move only if they have not been acquired yet. 